\title{
Information Uncertainty and the Post-Earnings Announcement Drift in Europe
}

\author{
Xavier Gerard \\ xavier.gerard@rbs.com \\ The Royal Bank of Scotland \\ 250 Bishopsgate, London UK, EC2M 4AA
}

\begin{abstract}
This paper investigates the relation between earnings announcement abnormal return, abnormal trading volume, and subsequent returns for a large sample of European firms. In addition to bringing new insights for the dynamics of the abnormal return and abnormal trading volume effects, our analysis provides out-of-sample confirmations of several prior US findings. We show that each measure of market surprise is positively related to future abnormal returns, and especially so when information uncertainty is high. These two effects appear to be complementary as each retain some incremental predicting power for future returns. Finally, our empirical evidence is not limited to small, illiquid, stocks; and it is robust to controlling for potential market microstructure biases.
\end{abstract}

JEL classification: M4, G12, G14

Keywords: Market efficiency; Trading Volume; High-Volume Premium; Post-Earnings Announcement Drift; Earnings Surprises; Information Uncertainty 


\section{Introduction}

Since Ball and Brown (1968), over forty years ago, an extensive body of mainly US academic research has documented a positive relation between earnings forecast errors, computed using either a time series approach or analyst estimates, and abnormal postannouncement returns. In contrast, due to several data limitations, the evidence for the postearnings announcement drift in Europe is relatively scarce. The historical coverage for analyst forecasts of interim numbers, as well as for the actual interim numbers released by the firms, is typically low or unreliable in Europe. Moreover, pan-European accounting studies are plagued by differences of accounting practices across member states.

This paper extends the US evidence to a large sample of European firms with annual as well as interim earnings announcements from 1997 to 2010. To avoid using analyst forecasts of interim numbers or the actual interim numbers released by the firm, we resort to some recent academic findings and quantify the degree of market surprise with some market related information, namely, the abnormal return and the abnormal trading volume at the time of the announcement. The use of market data implies that our metrics of market surprise can be easily computed for a large number of European firms. Moreover, by using market data we largely alleviate concerns related to differences of accounting practices across European countries.

The current predominant belief for the post-earnings announcement drift is that it is caused by some form of under-reaction to the information contained in earnings announcements. Although previous empirical work has focused on the earnings surprise, it has recently been noted that some important non-earnings information is also released at the time of the announcement. For example, firms provide information about components of earnings such as sales, and operating margins. Still further, earnings announcements tend to be accompanied by conference calls and press releases where valuable information is disseminated. Therefore, to the extent that the abnormal return captures a wide range of earnings and non-earnings related news, it could be argued that it is a broader measure of market surprise than traditional proxies.

In contrast with the post-earnings announcement drift of Ball and Brown (1968), the abnormal volume anomaly has been discovered recently. It refers to the outperformance of high volume stocks relative to low volume stocks following an earnings announcement. Explanations for this anomaly includes models of capital market equilibrium (Merton, 1987), behavioural biases arising from the limitations of individual investors to process large 
amounts of information (Barber and Odean, 2004), and risk-based arguments where the abnormal volume is seen as a proxy for opinion divergence (Garfinkel and Sokobin, 2006). Given that the empirical evidence for this effect is still limited, extending the analysis to the European market should help bring about some valuable insights.

Last but not least, we investigate the role played by information uncertainty in explaining the pay-offs associated with the abnormal volume and the abnormal return effects. Our proxy for information uncertainty is the idiosyncratic volatility of the securities in our sample. Hirshleifer (2001) posits that greater uncertainty combined with the lack of accurate feedback about fundamentals leave more room for behavioural biases. Although behavioural biases could well be accentuated in settings of higher information uncertainty, it is also possible that idiosyncratic risk constitutes a limit to arbitrage preventing investors from eliminating the anomalies. In any case, we predict that high idiosyncratic risk is associated with larger drifts, and this analysis should help further our understanding of the mechanisms at play behind these two empirical patterns.

Our results are four-fold. First, we find, in line with the US evidence, that a measure of market surprise, computed as the abnormal return around an earnings announcement, is positively related with future returns in Europe. The effect is not short lived as we show that firms with a positive surprise in one quarter continue to surprise the market, in the same direction, up to one year after the announcement.

Second, we are able to demonstrate, to our knowledge for the first time in Europe, the existence of a strong abnormal volume anomaly following earnings announcements. Firms with high abnormal volume around their earnings announcement date outperform low abnormal volume stocks for up to ninety days after the event. This outperformance is followed by a short period of underperformance, which strongly reverts one year after the event. Therefore, as with the abnormal return effect, we find that firms which surprise the market in one quarter continue to do so one year later. This evidence is echoed by patterns of abnormal trading volume following the earnings announcement date. Those firms with the highest abnormal trading volume in one quarter also experience a surge in their trading volume one year later. All in all, these results strongly suggest that investors in Europe fail to understand the implications of current announcements for future ones.

Third, as predicted, we show that the anomalies tend to generate stronger premiums when information uncertainty is larger. For instance, although significant abnormal returns are observed within stocks that have high and low idiosyncratic risk, we find that the abnormal 
return and abnormal volume effects are typically stronger within those stocks that experience the highest level of idiosyncratic volatility. Similarly, we show that the abnormal volume effect arises primarily during periods of high aggregate idiosyncratic risk.

Finally, the two effects appear to capture independent dimensions of the market surprise around an earnings announcement. Controlling for the degree of abnormal volume or abnormal return around an earnings announcement, we continue to find that the other effect is associated with positive future returns. Given their independent information contents we investigate their combined predictive power. We find that a trading strategy based on these two indicators of market surprise earns a monthly quintile spread return of approximately $0.70 \%$. The trading strategy is implemented with a monthly rebalancing frequency so that a signal is used for the first time on average two weeks after the earnings announcement, hence alleviating concerns that our findings are contaminated by potential market microstructure biases. Controlling for risk does not explain away the premium earned by the combined strategies. Moreover, these findings are not restricted to small firms, and they are robust to taking into account stock illiquidity and the volatility of stock returns over the announcement days.

The remainder of this paper is organised as follows. The next section discusses the relevant literature and motivates our analysis. The third section describes the sample data and introduce the main variables of this study. The fourth section presents and discusses our empirical findings. We test the robustness of our results in section five. Finally, the last section concludes the study.

\section{Literature Review and Motivations}

This analysis is related to prior US findings that show a positive association between measures of earnings surprise and future abnormal returns. The earnings surprise indicator, calculated at the time of an announcement, is typically defined as the scaled difference between the actual earnings figure and a proxy for market expectations computed using either analyst forecasts or the time series of prior earnings. Despite having been extensively researched since its discovery more than forty years ago by Ball and Brown (1968), the reason for the existence of the post-earnings announcement drift continues to be heavily debated. The prior empirical evidence offers little support for a risk-based explanation or potential flaws in research design (Bernard and Thomas, 1989). Instead, the current predominant belief for the post-earnings announcement drift is that it is caused by some form of under-reaction to the information contained in earnings announcements. The exact nature 
of the under-reaction remains vague however. Bernard and Thomas (1990) point out that the drift occurs at subsequent earnings announcement dates. This finding lead them and others (see for instance Ball and Bartov, 1996) to argue that investors fail to understand the implications of current earnings for future ones. However, Jacob et al (1999) offer an alternative interpretation of the causes of the post-earnings announcement drift when looking at the autocorrelation structure of forecast errors, and Livnat and Mendenhall (2006) put forward an explanation based on a more general hypothesis of under-reaction to earnings information.

Although the bulk of the prior evidence has focused on the earnings surprise, little attention has been paid to non-earnings information. However, considering non-earnings related news make sense for several reasons. For instance, Liu and Thomas (2000) show that a significant portion of the market reaction around earnings announcement is due to nonearnings related information. It is also obvious that some important non-earnings related news are released at the time of an announcement. For example, firms provide information about components of earnings such as sales, and operating margins (see Jegadeesh and Livnat, 2006). Still further, earnings announcements tend to be accompanied by conference calls and press releases where some additional valuable information is disseminated. Finally, a number of recent empirical findings suggest that market participants incorrectly value non-financial information. For instance, Ragjopal et al (2003) find that investors overestimate the valuation implications of order backlogs, while Gu (2005) and Deng et al (1999) show that investors systematically underweight patent counts, as well as the level change in patent citations.

In this study we follow Brandt et al (2006) and use as our first measure of market surprise the abnormal stock return around an earnings announcement date. To the extent that the abnormal return captures a wide range of earnings and non-earnings related news, both tangible and intangible, it could be argued that it is a broader measure of market surprise than previous indicators. In line with earlier findings, Brandt et al (2006) report a strong postearnings announcement drift when ranking stocks on the basis of their abnormal return at the time of the earnings announcement. However, it has to be noted that the magnitude of the price change around the earnings announcement could also be increasing in the information content of the news and decreasing in the degree of under-reaction.

Using market data as a proxy for the market surprise also achieves another objective, as it helps alleviate several data issues that have plagued European studies. First, the historical coverage for analyst forecasts of interim numbers, as well as for the actual interim numbers released by the firms, is typically low or unreliable in Europe. As a result the empirical 
evidence for the post-earnings announcement drift is relatively scarce in this region. One noticeable exception is the UK market, where Liu et al (2003) report the existence of the postearnings announcement drift. Like in the present study, the authors use a measure of price return as a proxy for the market surprise. They demonstrate that this proxy leads to a stronger drift than when analyst forecasts or the time-series of earnings are used instead. Second, although some country specific studies of the post-earnings announcement drift can be found in Europe, pan-European accounting research suffers from differences of accounting practices across member states. These differences are likely to blur the comparability of earnings surprises based on accounting numbers. In contrast, the use of market data should help circumvent these issues and enable a direct comparison of market surprises across European countries.

The second measure of market surprise used in this paper is the abnormal trading volume around an earnings announcement date. Lerman et al (2008) and Garfinkel and Sokobin (2006) find, in the US, a strong post-earnings announcement drift when ranking stocks on the basis of this indicator. These results echoe those of Gervais et al (2001) who show that a positive correlation exists between short-term abnormal trading volume and subsequent returns, even without conditioning on earnings announcements. Given the limited empirical evidence so far, extending the analysis to the European market should help bring about some valuable insights.

In contrast with the post-earnings announcement drift of Ball and Brown (1968), the abnormal volume effect has been discovered recently, so that a theoretical explanation for this result can be difficult to find. Nonetheless, a few theories stand out.

The work of Merton (1987) predicts that visibility induces positive returns. The key behavioural assumption behind this model is that investors use a security in their portfolio only if they know about it. Given that the equilibrium market value of a firm is a function of the aggregate demand for its shares, it is lower when fewer investors are aware of its existence. An unusually large trading volume on announcement day should increase investor awareness and in turn the demand for the shares of the firm.

According to Barber and Odean (2004), individual investors face a notable search problem when deciding which stocks to buy, so that they tend to focus on those stocks that catch their attention. They do not face the same issue when selling because they rarely short and tend to sell only the stocks that they already own. Hence, individual investors are net buyers of stocks in the news. An alternative representation of this theory is to imagine a 
downward sloping demand curve for the shares of the firms that shifts upward as a result of the attention-grabbing effect and intersects a fixed vertical supply curve at a higher price. To the extent that the abnormal trading volume "grabs" investor attention, this attention-driven buying could explain the post-earnings announcement drift. The positive returns on expected earnings announcement dates reported by Frazzini and Lamount (2006) are consistent with the "attention-grabbing” hypothesis. Similarly, Barber and Odean (2004) and Hirshleifer et al (2004) find that individual investors are net buyers in response to either positive or negative surprises. A further implication of the theory is that if individual investors push prices too high or prevent prices from falling in response to bad news, the ensuing performance of the attention-grabbing stocks will be poor.

Finally, a risk-based explanation can be given for the high-volume premium. For instance, Garfinkel and Sokobin (2006) argue that the abnormal volume around earnings announcements is an indicator of opinion divergence and therefore a risk factor that commends higher equilibrium returns.

While the exact reason for the existence of the post-earnings announcement drift is still unclear, looking at stocks characteristics has been insightful. For instance, the anomaly appears to be stronger within smaller, lower-priced, less liquid and more volatile securities that are followed by less sophisticated investors (see for instance Latane and Jones,1979; Bernard and Thomas, 1989; Bushan, 1994; Bartov et al, 2000; Mendenhall, 2004; Chordia et al, 2009). In other words, it is in within those stocks that suffer form larger degrees of information uncertainty and/or higher limits to arbitrage that we find the strongest evidence of abnormal behaviour. Several authors document how limits to arbitrage prevent investors form completely eliminating stock market inefficiencies (see for instance Shleifer and Vishny, 1997; Mendenhall, 2004; Pontiff, 2005). Moreover, Zhang (2006) demonstrates that investors under-reaction to public information is even more pronounced in cases of greater information uncertainty. The author's findings are in line with Hirshleifer (2001) who posits that greater uncertainty combined with the lack of accurate feedback about fundamentals leave more room for behavioural biases. We also expect the abnormal volume effect to be more pronounced in settings of higher information uncertainty, when the dispersion of beliefs about valuations is the largest. This is because the attention-grabbing hypothesis predicts that the opinion of the most optimistic investors prevails when a stock is in the news.

We use the idiosyncratic volatility of stock returns as a proxy for information uncertainty and the dispersion of beliefs about valuations. The variance of stock returns has been used as a measure of information quality in several prior studies (see for instance Rajgopal and 
Venkatachalam, 2005), but other proxies have been advocated as well. For instance, Francis et al (2007) use Dechow and Dichev's (2002) measure of earnings quality that captures the mapping of earnings into cash flows. The weaker the mapping, the poorer is the information quality. In line with expectations, the authors report a stronger post-earnings announcement drift within those stocks that suffer from larger degrees of information uncertainty. Given the compelling theoretical arguments for a link between post-earnings announcement drift and idiosyncratic risk, extending the evidence to the earnings announcement abnormal return and abnormal trading volume effects in Europe should help further our understanding of the mechanisms at play behind these two empirical patterns.

\section{Sample Description and Variable Definitions}

\subsection{Sample Description}

The universe for our study consists of exchange listed firms belonging to the FTSE AllWorld Developed Europe Index from 1997 to 2010. The use of such a well know index ensures that we do not need to make unrealistic assumptions regarding the accessibility of data to investors. To avoid a sample selection bias, we only consider a security in our analysis when it is included in the index. To avoid a survivorship bias, when a firm delist we assume a delisting return of $-100 \%$. We note, however, that our results are relatively insensitive to either eliminating these securities from our sample, or setting their returns to zero. Finally, we tested the robustness of our findings to the presence of outliers in the distribution of stock returns. In particular, we excluded returns in excess of 500\% per month. Our results proved to be robust to such outlier removal.

All the financial statement data in this paper is sourced form the Worldscope database, and the stock return data from the FactSet Price database. The interim and fiscal year-end earnings announcement dates are gathered from the FactSet Estimates database. In Figure 1 we plot, every month, the actual number as well as the proportion of stocks in the universe with an earnings announcement in the past four months. We consider both interim and fiscal year-end report dates. Interim report dates comprise semi-annual announcements as well as announcements for quarter one to quarter three.

\section{[FIGURE 1 ABOUT HERE]}

We will show later in this study that a factor based on earnings announcement surprises has a predictive power that lasts for more than 60 days. Moreover, we use widely available 
market data to compute our indicators of market surprise, so that the main constraint that we face in terms of data coverage is the availability of interim and fiscal year-end report dates. Therefore, Figure 1 gives an indication of the historical coverage of an hypothetical trading strategy that attempts to capitalise on market surprises at the time of an earnings announcement. Based on Figure 1, we can infer that the historical coverage of this strategy is large since the beginning of our sample period. We also note some seasonal patterns in the relative and absolute coverage of announcement dates. This is due to the fact that in some countries (notably the UK, France, and Switzerland) a significant portion of firms report on a semi-annual basis only.

\section{[FIGURE 2 ABOUT HERE]}

In Figure 2, we distinguish between the proportion of interim and fiscal year-end announcements in our universe each month. We can see that the proportion of interim report dates is large since the beginning of our sample period. The larger proportion of fiscal yearend announcements in 2010 is due to our sample ending in June that year. Finally, an investigation of Figure 3 indicates the presence of two clusters of announcements, one from February to May, and one from July to November. In comparison, January, June and December tend to be relatively “quiet” months.

\section{[FIGURE 3 ABOUT HERE]}

\subsection{Variable Definitions}

Our first indicator of market surprise is the abnormal return recorded over a three-day window centred on the announcement date. The exact definition used in this paper is taken from Brandt et al (2008). It is calculated for firm $i$ at time $t+1$, where $t$ is the report date, as follows:

$$
\text { Abnormal Return } n_{t+1}^{i}=\prod_{j=t-1}^{t+1}\left(1+r_{j}^{i}\right)-\prod_{j=t-1}^{t+1}\left(1+r_{\text {bench }_{j}}\right)
$$

The benchmark return for firm $i$ is the equally weighted return of a sample of firms that fall in the same Size (market capitalisation), Book-to-Market and Momentum terciles prior to the announcement. 
The second indicator of market surprise follows Lerman et al (2008). It is the average daily share volume over a three-day window centred on the announcement date divided by the average daily share volume estimated over days -8 through -63 . It is calculated for firm $i$ at time $t+1$, where $t$ is the report date, as follows:

$$
\text { Abnormal Volume }_{t+1}^{i}=\left\{\frac{1}{3} \sum_{j=t-1}^{t+1} \# \text { Shares Traded }_{j}^{i} / \frac{1}{56} \sum_{j=t-63}^{t-8} \# \text { Shares Traded }_{j}^{i}\right\}-1
$$

Finally, the last important variable in this study is the idiosyncratic volatility of stock returns, the conditioning variable for the returns of our trading strategies. The specific risk of each security is calculated using 52 weeks of data and the following Carhart (1997) fourfactor model:

$$
r_{i}^{t}-r_{f}^{t}=\alpha_{i}^{t}+\beta_{1, i}^{t} \cdot\left(r_{m}^{t}-r_{f}^{t}\right)+\beta_{2, i}^{t} \cdot S M B^{t}+\beta_{3, i}^{t} \cdot H M L^{t}+\beta_{4, i}^{t} \cdot U M D^{t}+\varepsilon_{i}^{t}
$$

where $S M B, H M L$, and $U M D$ are the Fama-French Size, Book-to-Market and Momentum factors adapted for the European market; and where $r_{m}$ and $r_{f}$ are respectively the market return and the risk-free rate.

\section{Empirical Findings}

\subsection{The Earnings Announcement Abnormal Return and Abnormal Volume Effects}

In Table 1 and Figure 4, we report the adjusted post-announcement returns of each quintile of firms ranked on their earnings announcement abnormal return (Panel A) and abnormal volume (Panel B). To avoid a look-ahead bias, quintile rankings are formed on the basis of the past three months' earnings announcement abnormal returns and abnormal volume. The post-announcement returns of each quintile are market-adjusted and characteristics-adjusted. The characteristics adjustment follows the methodology of Lyon, Barber and Tsai (1999). To compute the characteristics benchmark, we match each event firm to a portfolio of securities that fall in the same Size (market capitalization), Book-to-Market and Momentum terciles prior to the announcement. Finally, to avoid biasing our statistical tests, in Table 1, we consider the earnings surprise of a firm only if its post-event returns do not overlap with those of its previous surprise. 


\section{[TABLE 1 ABOUT HERE]}

Irrespective of whether we control for the market or characteristics associated with future returns, we find, for both measures of market surprise, a significant post-announcement drift up to 60 days following the event. The premium of the abnormal return strategy is strong up to 20 days after the announcement, and tapers off thereafter. The market-adjusted quintile spread return is equal to $0.57 \%$ in the five days that follow the event and increases to $1.66 \%$ when considering a 60-day holding period. The predictive power of the abnormal volume strategy appears to be more prolonged. The market-adjusted quintile spread return of this strategy is equal to $0.54 \%$ in the five days that follow the earnings announcement, and it increases to $2.82 \%$ when considering a 60 -day holding period.

\section{[FIGURE 4 ABOUT HERE]}

Interestingly, we find that the premiums of the abnormal return and abnormal volume strategies are driven to a large extent by the outperformance of the quintile five of earnings announcement abnormal returns (i.e. those stocks with a positive surprise) and abnormal volume, respectively. For instance, the market-adjusted return of the quintile five of abnormal return is equal to $1.78 \%$ when considering a 60 -day holding period, while it is only equal to $0.12 \%$ for quintile one. Similarly, we find a market-adjusted return of $2.67 \%$ for quintile five of abnormal volume and only $-0.15 \%$ for quintile one. The characteristics matching reduces this asymmetry. However, at short horizons, the large contribution of the quintile five of earnings announcement abnormal return and abnormal volume can be observed for this benchmark as well. These findings are particularly noteworthy since many anomalies tend to perform more strongly on the short rather than on the long side. One of the explanations generally put forward for this phenomenon is that short-sales constraints can impede the timely adjustment of prices to negative information. Another implication of these findings is that earnings announcements in Europe are on average associated with positive future returns, at least over the short term. Frazzini and Lamont (2006), among others, have also reported a positive association between earnings announcements and future stock returns in the US.

Figure 4 (Panel B) also reports the pre-announcement returns of each quintile of earnings announcement abnormal volume. Interestingly, we can see that firms that fall in quintile five of earnings announcement abnormal volume underperform in the 60-day period prior to the event, while low abnormal volume stocks are relative outperformers. To the extent that the quintile five of abnormal volume contains a disproportionally large number of firms with low 
"normal” volume and quintile one an unusually large number of high "normal” volume stocks, it could be argued that Figure 4 (Panel B) captures the well-documented positive contemporaneous correlation between the trading volume of a stock and its return (see among others Karpoff, 1987). These findings are worth pointing out because they raise the possibility that the earnings announcement abnormal volume effect exists despite the medium-term price momentum anomaly.

\section{[TABLE 2 ABOUT HERE]}

In Table 2, we look more closely at the consistency through time of the premiums earned by each strategy. To avoid biasing our statistical tests, we control for overlapping returns as in Table 1. We find that the abnormal return strategy (Panel A) earns a positive premium in most years, the only exceptions being 1997, 2002 and 2009. While we also find the premiums of the abnormal volume strategy to be positive in most years, we note that these are particularly strong during the financial crisis.

\section{[TABLE 3 ABOUT HERE]}

In Figure 5 and Table 3 we show the cumulative difference in the adjusted long-term performance of stocks that fall in quintile five and stocks that fall in quintile one of earnings announcement abnormal returns (Panel A) and abnormal volume (Panel B). We first show that the premium of the earnings announcement abnormal return strategy, earned in the days following the announcement, is not short lived. While the adjusted quintile spread performance is at times flat during the 300-day period that follows the earnings announcement, we do not find any evidence of a reversal effect. Second, we report some interesting seasonality for the earnings announcement abnormal return effect. The strategy earns significant abnormal returns on the following quarter and on the same quarter one year later. In other words, stocks that surprise the market in one quarter continue to do so, in the same direction, in the following quarter and in the same quarter one year later. The premium two quarters away from the announcement date is somewhat smaller than the ones observed one quarter and one year after the announcement. We cannot find any significant premium on the third following quarter. Therefore, investors appear to under-react to the information contained in earnings announcement, and they fail to understand the implications of past surprises for future ones, with a significant portion of the adjustment to past surprises occurring around future announcements. As a result, the performance of the earnings announcement abnormal return strategy looks like a set of stairs where the picks occur around the following announcement dates. 


\section{[FIGURE 5 ABOUT HERE]}

As with the abnormal return effect, we find, looking at Figure 5 and Table 3 (Panel B), that the premium earned by the abnormal volume strategy in the days following the announcement is not short lived. The cumulative difference in the adjusted long-term performance of stocks that fall in respectively quintile five and quintile one of earnings announcement abnormal volume experiences an upward drift until 90 days after the event. From 180 days following the announcement to the end of the year, we observe some underperformance, suggesting that the market might be correcting some initial over-reaction. Over this period, the strategy returns retract by around 19\% and 13\% when considering, respectively, market-adjusted returns and characteristics-adjusted returns. However, this period of underperformance is followed by a significant pick-up in the strategy returns, starting 250 days after the event. Stocks that surprise the market in one quarter seem to continue to do so in the same quarter one year later.

\section{[FIGURE 6 ABOUT HERE]}

Finally, in Figure 6, we show the median abnormal volume following the earnings announcements of each quintile of earnings announcement abnormal volume. The patterns in these graphs tell a very similar story to that of Figure 5 (Panel B). Stocks that fall in quintile five of earnings announcement abnormal volume tend to experience large increases in their abnormal trading volume in the same quarter one year later. Note that in Panel A we keep the normal trading volume constant throughout the period. It is equal to the normal trading volume on the event date. In contrast, in Panel B, we use a moving average over the postevent days. Using this metric, we find that the difference between quintile one and quintile five median abnormal volume, over a 30-day window falling one year after the event, is significant at the $1 \%$ level based on a Wilcoxon rank sum test. All in all, our results suggest that firms tend to issue important news on the same quarter every year. However, despite this recurrent pattern, investors appear to be systematically surprised by these announcements.

\subsection{The Role of Information Uncertainty}

One of the theoretical explanations for the post-earnings announcement drift is that investors under-react to public information. Zhang (2006) demonstrates that this underreaction is even more pronounced in cases of greater information uncertainty. It could also be argued that we should observe the greatest initial outperformance for firms that grab investor 
attention in settings where the dispersion of beliefs about valuations is the largest. This is because the theory predicts that the opinion of the most optimistic investors prevails when a stock is in the news. Finally, our measure of information uncertainty might also represent a limit to arbitrage preventing investors from eliminating market inefficiencies. In any case, this analysis should help further our understanding of the mechanisms at play behind the earnings announcement abnormal return and abnormal volume effects.

We use the specific volatility of stock returns as a proxy for information uncertainty and the dispersion of beliefs about valuations. This is estimated based on the Carhart (1997) fourfactor model of equation (3), using a weekly frequency and a one-year estimation period. In Table 4, we intersect independent rankings of market surprise, based on either earnings announcement abnormal return or abnormal volume, and idiosyncratic volatility at the time of the earnings announcement. We then explore the predictive power of the abnormal return and abnormal volume effects in each quintile of stock specific risk. In Table 5 we look at the performance of the strategies following periods of high and low aggregate specific risk. Bekaert et al (2010) show, for a large sample of developed countries, that aggregate idiosyncratic volatility is well described by a stationary, mean reverting process with occasional shifts to a higher mean, higher variance regime. However, characterizing precisely the dynamics of aggregate idiosyncratic volatility is beyond the scope of this paper. Instead, we attempt to only capture an indication of the volatility regime, by classifying each month in our sample into periods of either high or low idiosyncratic risk. A period of high specific risk is one where the previous one-year aggregate weekly idiosyncratic risk, for the firms in the index, is larger than the average weekly idiosyncratic risk from one year ago to four years ago ([-1Y, -4Y]), five years ago ([-1Y, -5Y]), or six years ago ([-1Y, -6Y]). Longer horizons for the estimation of the normal level of idiosyncratic risk should capture more dramatic changes in the state of the market, but also result in a less dynamic indicator of market states. In Figure 7, we present the annualised aggregate idiosyncratic volatility estimated at the end of each month in our study period, as well as the dynamics of each volatility benchmark. The outcomes of this classification exercise appear to be quite intuitive. The tech bubble years and the financial crisis are classified as periods of high aggregate idiosyncratic volatility, while the period in-between corresponds to the bulk of the low volatility regimes.

\section{[FIGURE 7 ABOUT HERE]}

As in the previous section, to avoid a look ahead bias, earnings announcement abnormal return and abnormal volume quintile rankings are formed on the basis of the past three months' values. The same approach is used to allocate event firms to a quintile of stock 
specific risk, and a surprise is classified into a high or low state of aggregate idiosyncratic risk on the basis of the market state prevailing at the end of the month preceding the earnings announcement. Finally, the post-announcement returns of the firms in our universe are market-adjusted and characteristics-adjusted.

\section{[TABLE 4 ABOUT HERE]}

While we find that information uncertain plays an important role in explaining the magnitude of the premiums earned by the strategies, the conditional dynamics of each effect appear to differ markedly. In Table 4, we see, when considering a 20-day and a 60-day holding period, that a strategy based on earnings announcement abnormal return (Panel A) works significantly better within highly volatile stocks than within stocks with low volatility. For instance, at a 60-day horizon, the market-adjusted premium for the strategy is $3.31 \%$ greater within high volatility stocks than within their low volatility counterparts. When considering a short horizon, however, no significant difference can be found. The reverse appears to be true, in Panel B, for the earnings announcement abnormal volume effect. When considering a short horizon, the strategy works significantly better within stocks that have high idiosyncratic risk. In the 5-day period that follows an earnings announcement, we find that the market-adjusted premium earned by high volatility stocks dominates that of low volatility stocks by as much as $1.29 \%$. At longer horizons, however, no significant difference can be found between each group of stocks.

\section{[TABLE 5 ABOUT HERE]}

In Table 5, we show that the market state conditioning is very effective for strategies based on earnings announcement abnormal volume. For a 60-day holding period, the characteristics-adjusted return of the abnormal volume strategy is $3 \%$ higher following months with high average idiosyncratic volatility than months with low average idiosyncratic volatility. However, at short horizons, the volatility conditioning looses its effectiveness. This true as well, for all holding periods, when considering the earnings announcement abnormal return effect. All in all, these results help illustrate the different nature of each anomaly. In the next section we further document how each effect captures an independent dimension of market surprise.

4.3 The Earnings Announcement Abnormal Return \& Abnormal Volume Effects: Complements or Substitutes? 
In Table 6, we intersect independent rankings based on earnings announcement abnormal return and abnormal volume, and measure, over different holding periods, the abnormal performance of stocks that fall in each intersection. To avoid a look-ahead bias, quintiles are formed on the basis of the past three months' abnormal return and abnormal volume values. Finally, as in previous sections, we report abnormal returns computed as the excess returns of the stocks over the market, and over a characteristics-benchmark.

\section{[TABLE 6 ABOUT HERE]}

First, we find that the earnings announcement abnormal volume effect is positively related to future returns for every quintiles of earnings announcement abnormal return, and irrespective of whether we look at short or long holding periods. The evidence for the marginal impact of the abnormal volume is, however, more statistically significant when considering longer holding periods.

Second, it appears that earnings announcement abnormal returns also help differentiate winners and losers after controlling for abnormal volume. The quintile spread returns earned by this strategy in each intersection of abnormal volume are typically positive, and in several instances also statistically significant. While some evidence of marginal contribution can be found for each holding period, the incremental predictive power of the earnings announcement abnormal return strategy is particularly noticeable over the 20-day period that follows the announcement. Over this period, the strategy earns a positive quintile spread return in each quintile of abnormal volume. These quintile spread returns are also typically statistically significant.

All in all, these results suggest that the earnings announcement abnormal return and abnormal volume effects capture different dimensions of earnings surprises. Therefore, our empirical evidence seems to confirm the idea that these two empirical patterns are the results of distinct behavioural biases.

\subsection{Trading Strategy with Monthly Rebalancing}

Given their independent information contents we investigate in this section the combined predictive power of the earnings announcement abnormal return and abnormal volume effects. To this end, we devise an implementable trading strategy where stocks are ranked, at the end of each month, on the basis of their latest earnings announcement abnormal return and abnormal volume, provided that the last announcement was made no later than four months 
ago. For the sake of clarity, and to avoid data mining our sample, we then use an equal blend of these two rankings to create a quintile spread portfolio that we hold until the end of the following month, when the ranking process is repeated. The time sequence of ranking and trading periods is described in Figure 8, and our monthly measure of earnings surprise is simply:

$$
\text { Earnings Surprise } e_{t}^{i}=0.5 \cdot\left(\text { Abnormal Return } n_{t}^{i}+\text { Abnormal Volume }_{t}^{i}\right)
$$

The imposition of only a monthly rebalancing frequency for our trading strategy should help mitigate concerns that our findings are contaminated by potential market microstructure biases. Indeed, under this specification, a score is used for the first time on average two weeks after the earnings announcement.

\section{[FIGURE 8 ABOUT HERE]}

For our trading strategy to be easily implementable, it is important that it works within large-capitalisation names. To ascertain that this is the case, we also run the strategy within the largest capitalisations of the FTSE All-World Developed Europe Index. This is defined as the top $50 \%$ of stocks in terms of market capitalisation each month. Moreover, given our earlier findings, we investigate the interaction of this strategy with month-end rankings on idiosyncratic risk. Firms with high and low idiosyncratic risk have values for their specific risk that fall above and below the median value, respectively. We also distinguish between periods of high and low aggregate specific risk on the basis of idiosyncratic risk rankings at the end of every months. As in section 4.2, a period of high aggregate specific risk is one where the previous one-year average weekly idiosyncratic risk is larger than the average weekly idiosyncratic risk from one year ago to four years ago ([-1Y, -4Y]), five years ago ([$1 \mathrm{Y},-5 \mathrm{Y}])$, or six years ago ([-1Y, $-6 \mathrm{Y}])$. Finally, in addition to presenting abnormal returns that are characteristics-adjusted, we compute the alpha of the strategy as specified in the following Carhart (1997) four-factor model:

$$
r_{\text {port }}^{t}-r_{f}^{t}=\alpha+\beta_{1} \cdot\left(r_{m}^{t}-r_{f}^{t}\right)+\beta_{2} \cdot S M B^{t}+\beta_{3} \cdot H M L^{t}+\beta_{4} \cdot U M D^{t}+\varepsilon^{t}
$$

where $S M B, H M L$, and $U M D$ are the Fama-French Size, Book-to-Market and Momentum factors adapted for the European market; and where $r_{m}$ and $r_{f}$ are respectively the market return and the risk-free rate. Equation (5) is ran using the monthly returns from the trading 
strategy of Figure 8, where the top quintile of earnings surprises is bought and the bottom quintile sold.

\section{[TABLE 7 ABOUT HERE]}

The results for this analysis are presented in Tables 7 to 9 . The earnings surprise strategy generates a large raw quintile spread return of $0.70 \%$ per month. Neither the characteristics matching nor the systematic risk controls of the Fama-French / Carhart four-factor model explain away this premium. We find a significant abnormal return of $0.69 \%$ for the strategy in Table 7, and a significant alpha of $0.42 \%$ in Table 8.

\section{[TABLE 8 ABOUT HERE]}

The premium earned by the strategy is particularly large within small stocks. The raw (abnormal) quintile spread return is equal to $0.84 \%$ (0.81\%) within that subset of the universe. However, even after considering only the largest capitalisations, we continue to find that a trading strategy based on earnings surprises generates significant monthly quintile spread returns in Europe. The raw (abnormal) quintile spread return earned in the largest capitalisation subset of our universe is equal to $0.58 \%$ (0.56\%). Similar conclusions can be drawn when considering the alpha of the strategy in Table 8. To appreciate the economic significance for the differential performance of the trading strategy within each capitalisation subset, one needs to bear in mind that the largest capitalisation names typically experience significantly lower transaction costs. In unreported results, we found that our trading strategy generates a monthly turnover of approximately $60 \%$, so that a difference in unit transaction costs of only $0.20 \%$ would suffice to explain the difference in the raw performance of the strategy within large and small capitalisation stocks (the average transaction cost is equal to: $T C=2 \times 0.6 \times$ Unit TC ).

The result that large firms are subject to behavioural biases such as the under-reaction to public information or the attention-grabbing effect might seem surprising. Similarly, to the extent that investors are already aware of large firms, it is at first unclear how an earnings announcement could significantly increase their visibility. However, it is reasonable to argue that for an announcement to catch investor attention a sufficient amount of publicity is required. In fact, small stocks whose announcements are rarely mentioned may actually find it hard to grab investor attention. 
[TABLE 9 ABOUT HERE]

Last but not least, we show some results for the idiosyncratic volatility conditioning. As expected, we find, in Tables 7 and 8, that the trading strategy earns a larger premium within those stocks that have higher levels of idiosyncratic risk. That said, even in the low idiosyncratic volatility subset, we continue to find, in Table 7, that a trading strategy based on earnings surprises generates large raw and abnormal monthly quintile spread returns. The positive premium for the low volatility subset of the universe loses, however, its statistical significance once we control for the Fama-French / Carhart factors. Finally, in Table 9, we see that the premiums earned by the earnings surprise strategy tend to cluster around periods of high aggregate idiosyncratic risk, as identified in Figure 7. When the normal level of volatility is estimated over a four-year period ([-1Y, $-4 \mathrm{Y}])$, the raw (abnormal) quintile spread return earned during high volatility regimes is equal to approximately $1.16 \%(1.11 \%)$, while it is equal to $0.27 \%$ (0.29\%) when volatility is low.

\section{Robustness Tests}

\subsection{The Trading Strategy Returns and Stock Illiquidity}

Chordia et al (2009) report that the post-earnings announcement drift in the US is prevalent mainly within relatively illiquid stocks. To the extent that market capitalisation does not perfectly control for stock illiquidity, it could be that the significant quintile spread return earned by the earnings surprise strategy within the largest capitalisation names disappears once stock illiquidity is taken into account explicitly. To test whether this is the case, we investigate, within the large capitalisation subset of our universe, the performance of the earnings surprise strategy for those stocks with an illiquidity ratio that falls in the bottom $50 \%$ of values for that group. The measure of illiquidity used in this study is similar to that of Chordia et al (2009). The authors follow Amihud (2002) who measures illiquidity as the daily absolute return per dollar of daily trading volume:

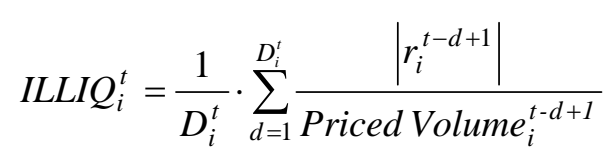

where $r$ is the daily return, Priced Volume is the priced daily trading volume and $D$ is the number of days in the month for which data is available. A stock is allocated in the high liquidity subset if its illiquidity score falls below the median value that month. 
The results of this analysis are presented in Table 7. Controlling for illiquidity only marginally reduces the quintile spread return of the strategy within the largest capitalisation subset of the universe. The raw and abnormal returns earned by the strategy continue to be both economically as well as statistically significant, hence possibly suggesting that our control for market capitalisation already captures most of the difference in firm liquidity.

\subsection{Earnings Announcement Abnormal Volume and Absolute Returns}

Several authors have documented a contemporaneous correlation between the trading volume of a stock and its absolute return. Since absolute return closely proxy for stock volatility, it could be argued that the abnormal volume effect only reflects this risk premium.

To assess whether this is the case, we first run the monthly strategy of Figure 8, using the earnings announcement abnormal volume and the absolute announcement return on the threeday announcement window. Second, every months we run two cross-sectional regressions of the earnings announcement abnormal volume of each stock against their absolute announcement return. The first regression is simply:

$$
\text { Abnormal Volume }{ }_{t}^{i}=\alpha_{t}+\beta_{t} \cdot \text { Absolute Return } n_{t}^{i}+\varepsilon_{t}^{i}
$$

The second regression recognises that the relation between volume and the absolute value of returns may differ according to the sign of the return (see Karpoff, 1987). Therefore, each month we run:

$$
\text { Abnormal Volume }{ }_{t}^{i}=\alpha_{t}+\beta_{t}^{+} \cdot \text { Absolute Return }{ }^{+}{ }_{t}+\beta_{t}^{-} \cdot \text { Absolute Return }^{-i}+\varepsilon_{t}^{i}
$$

The residuals of these regressions are then used in monthly strategies, to assess whether, controlling for absolute return, the abnormal volume strategy continues to generate a significant return.

\section{[TABLE 10 ABOUT HERE]}

Table 10 shows that the absolute return strategy fails to earn a significant quintile spread return over the period of our study. In contrast, the abnormal volume strategy generates a significant raw (abnormal) quintile spread return of around $0.51 \%(0.38 \%)$ over the study 
period. Moreover, controlling for the absolute return around the announcement reduces but does not eliminate the significance of the premium earned by the earnings announcement abnormal volume strategy.

\section{Conclusion}

In this paper we add to the burgeoning literature on the earnings announcement abnormal return and abnormal volume effects, by studying these anomalies in a large sample of European firms that spans a period of 14 years. We are able to demonstrate that these two effects generate large premiums over our study period. They also appear to be relatively independent phenomena as each retain some incremental predicting power for future returns.

Moreover, we show that information uncertainty plays an important role in determining the magnitude of the premiums earned by these strategies. First, we find that both anomalies generate stronger abnormal returns within those stocks that experience larger degrees of idiosyncratic volatility. Second, we show that the abnormal volume effect arises primarily during periods of high aggregate idiosyncratic risk. These findings are in line with the view that behavioural biases are exacerbated in settings of heightened information uncertainty. An alternative, but not necessarily conflicting, explanation is that idiosyncratic volatility constitutes a limit to arbitrage, preventing investors from eliminating the premiums.

To conclude, we believe that our results have important implications to both academics and practitioners. Our comparative analysis of the dynamics of the earnings announcement abnormal return and abnormal volume effects in Europe makes a significant contribution to our understanding of each anomaly. We also provide valuable insights to practitioners interested in implementing trading strategies based on earnings surprises in the European market, where data issues had limited the scope of previous research. 


\section{References}

Amihud Y. (2002), "Illiquidity and stock returns: Cross-section and time-series effects", Journal of Financial Markets, 5, p. 31-56

Ball R. and Bartov E. (1996), “How naïve is the stock market’s use of earnings information?”, Journal of Accounting and Economics, 21, p. 319-337

Ball R. and Brown P. (1968), “An empirical evaluation of accounting income numbers”, Journal of Accounting Research, 6, p. 159-178

Barber B. and Odean T. (2004), "All that glitters: The effect of attention and news on the buying behavior of individual investors”, Financial Analyst Journal, p. 41-55

Bartov E., Radhakrishnan S. and Krinsky I. (2000), "Investor sophistication and patterns in stock returns after earnings announcements”, The Accounting Review, 75, p. 43-63

Bekaert G., Hodrick R.J. and Zhang X. (2010), “Aggregate idiosyncratic volatility”, CEPR discussion paper

Bernard V. and Thomas J. (1989), "Post-earnings drift: Delayed price response or risk premium?” Journal of Accounting Research, 27, p. 1-36

Bernard V. and Thomas J. (1990), "Evidence that stock prices do not fully reflect the implications of current earnings for future earnings”, Journal of Accounting and Economics, 13, p. 305-340

Brandt M.W., Kishore R., Santa-Clara P. and Venkatachalam M. (2008), "Earnings announcements are full of surprises”, working paper

Bushnan R. (1994), “An informational efficiency perspective on the post-earnings announcement drift”, Journal of Accounting and Economics, 18, p. 45-65

Carhart M. (1997), “On persistence in mutual fund performance”, The Journal of Finance, 52, p. $57-83$ 
Chordia T., Goyal A., Sadka G., Sadka R. and Shivakumar L. (2009), "Liquidity and the postearnings-announcement-drift”, Financial Analysts Journal, 65, p. 18-32

Dechow P. and Dichev I. (2002), “The quality of accruals and earnings: The role of accrual estimation errors”, The Accounting Review, 77, p. 35-39

Deng Z., Lev B. and Narin F. (1999), “Science and technology as predictors of stock performance”, Financial Analysts Journal, 55, p. 20-32

Francis J., LaFond R., Olsson P. and Schipper K. (2007), “Information uncertainty and postearnings-announcement-drift”, Journal of Business Finance and Accounting, 34, p. 403-433

Frazzini A. and Lamont O. (2006), “The earnings announcement premium and trading volume”, NBER working paper

Garfinkel J.A. and Sokobin J. (2006), "Volume, opinion divergence, and returns: A study of post-earnings announcement drift”, Journal of Accounting Research, 44, p. 85-112

Gervais S., Kaniel R. and Mingelgrin D.H. (2001), “The high-volume return premium”, The Journal of Finance, 56, p. 877-919

Gu F. (2005), “Innovation, future earnings, and market efficiency”, Journal of Accounting, Auditing and Finance, 20, p. 385-418

Hirshleifer D. (2001), “Investor psychology and asset pricing”, The Journal of Finance, 56, p. 1533-1596

Hirshleifer D., Myers J.N., Myers L.A. and Teoh S.H. (2004), "Do individual investors drive post-earnings announcement drift? Direct evidence from personal trades”, working paper

Jacob J., Thomas L. and Sabino J. (1999), “Autocorrelation structure of forecast errors from time-series model: Alternative assessments of the causes of post-earnings announcement drift”, Journal of Accounting and Economics, 28, p. 329-358

Jegadeesh N. and Livnat J. (2006), "Post-earnings-announcement drift: The role of revenue surprises”, Financial Analyst Journal, 62, p. 22-34 
Karpoff J. (1987), “The relation between price changes and trading volume: A survey”, Journal of Financial and Quantitative Analysis, 22, p. 109-126

Latane H.A. and Jones C.P. (1979), “Standardized unexpected earnings - 1971-77”, The Journal of Finance, 34, p. 717-724

Lerman A., Livnat J. and Mendenhall R.R. (2008), “The high-volume return premium and post-earnings announcement drift', working paper

Liu J and Thomas J. (2000), “Stock returns and accounting earnings”, Journal of Accounting Research, 38, p. 71-101

Liu W., Strong N. and Xu X. (2003), "Post-earnings-announcement drift in the UK", European Financial Management, 9, p. 89-116

Livnat J. and Mendenhall R.R. (2006), “Comparing the post-earnings announcement drift for surprises calculated from analyst and time series forecasts”, Journal of Accounting Research, 44, p. $177-205$

Lyon J.D., Barber B.M. and Tsai C.L. (1999), "Improved methods for tests of long-run abnormal stock returns”, The Journal of Finance, 54, p. 165-201

Mendenhall R.R. (2004), “Arbitrage risk and post-earnings-announcement drift”, Journal of Business, 77, p. 875-894

Merton R.C. (1987), “A simple model of capital market equilibrium with incomplete information”, The Journal of Finance, 42, p. 483-510

Pontiff J. (2006), “Costly arbitrage and the myth of idiosyncratic risk”, Journal of Accounting and Economics (42), p. 25-52

Ragjopal S., Shleivin T. and Venkatachalam M. (2003), "Does the stock market fully appreciate the implications of leading indicators for future earnings? Evidence from order backlog”, Review of Accounting Studies, 8, p. 461-492

Rajgopal S. and Venkatachalam M. (2005), "Financial reporting and idiosyncratic return volatility over the last four decades”, working paper 
Shleifer A. and Vishny R. (1997), "The limits of arbitrage”, The Journal of Finance (52), p. 35-55

Zhang X.F. (2006), “Information uncertainty and stock returns”, The Journal of Finance, 61, p. $105-137$ 
Figure 1: Coverage in the FTSE All-World Developed Europe Index

The coverage measures the \# (\%) of stocks in the index with an earnings announcement (interim or fiscal year-end) in the last four months.

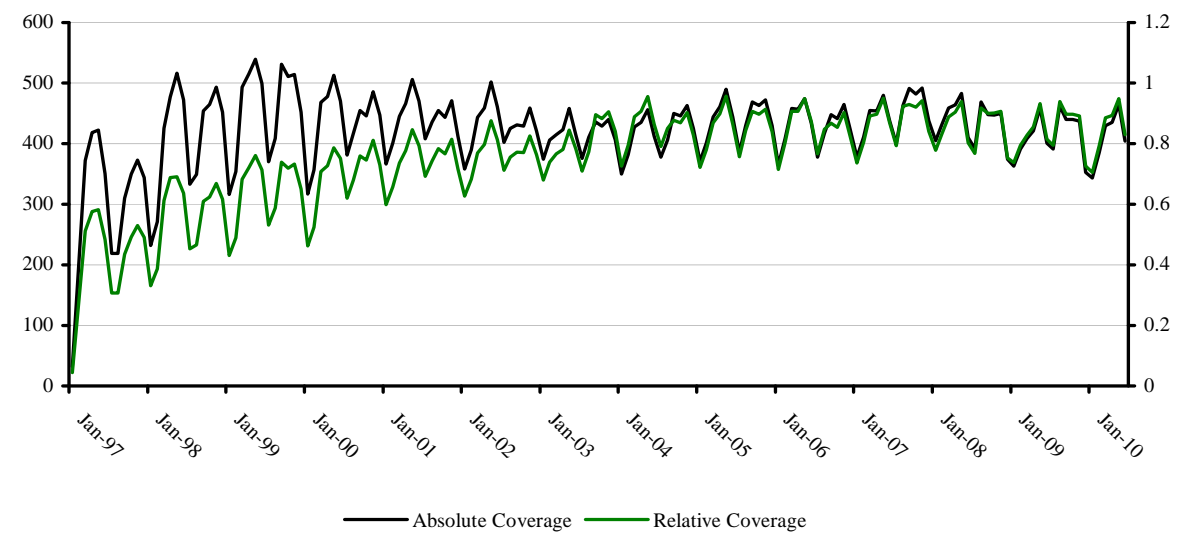

Figure 2: Seasonal Patterns of Announcements

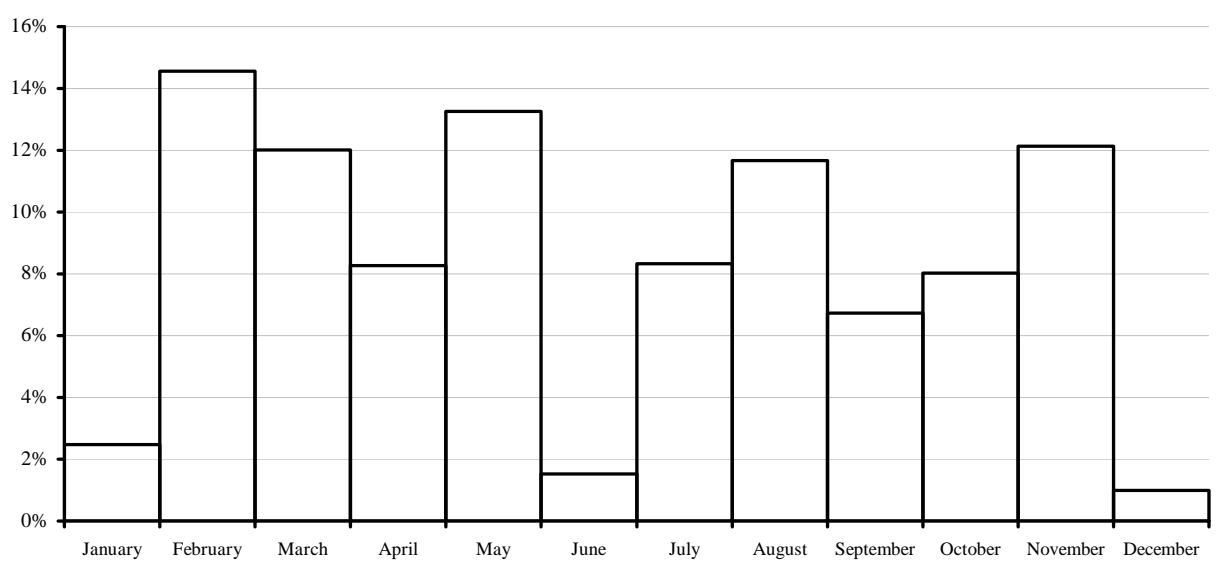

Figure 3: Frequency of Announcement Types

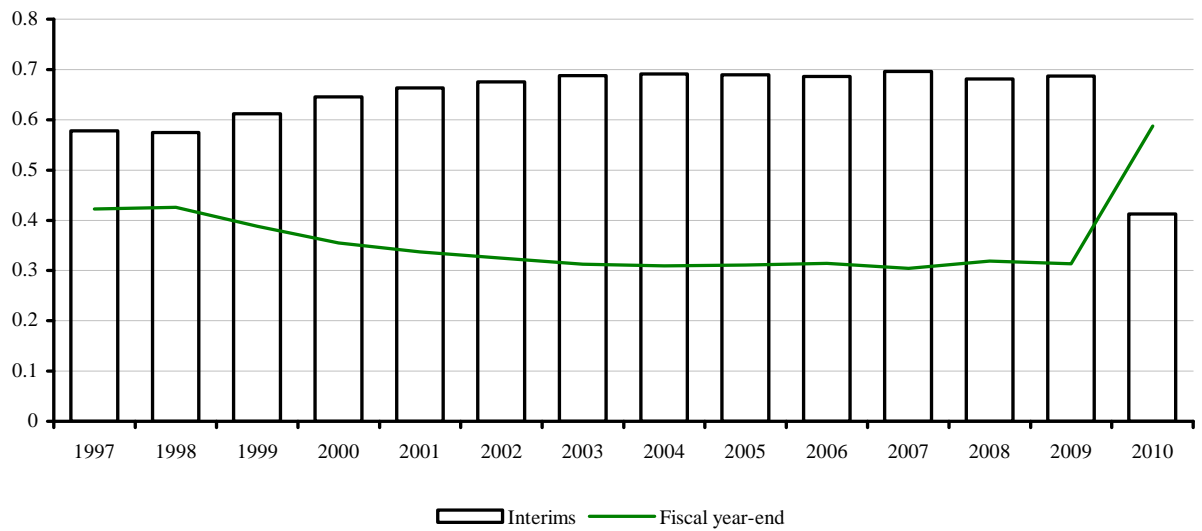


Figure 4: Post-Earnings Announcement Drift

Figure 4 shows the cumulative post-announcement returns of each quintile of firms ranked on their earnings announcement abnormal return (Panel A) and abnormal volume (Panel B). Returns are market-adjusted. To avoid a look-ahead bias, quintiles are formed on the basis of the past three months' values.

Panel A: Earnings Announcement Abnormal Return

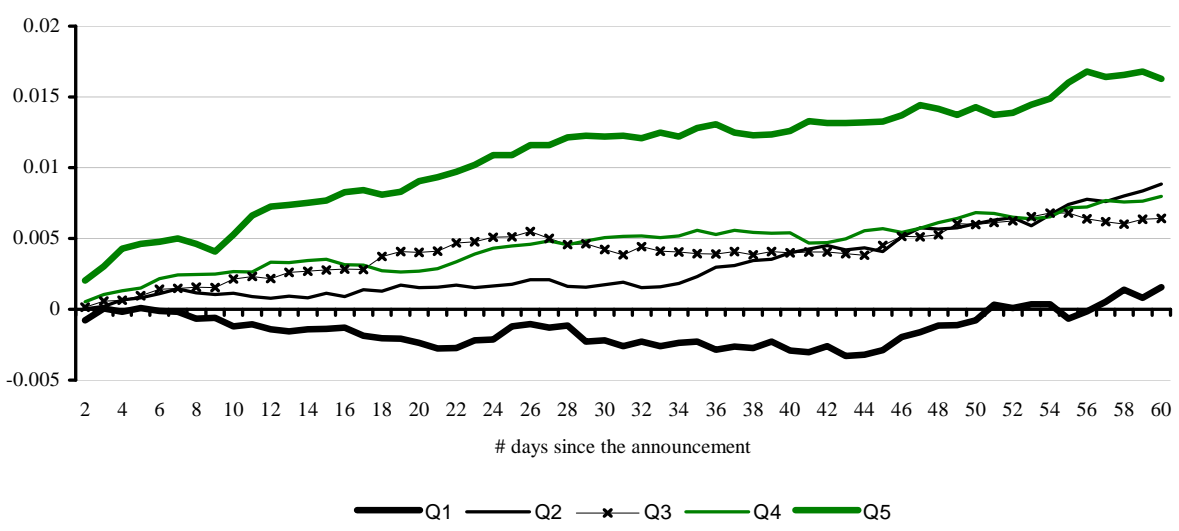

Panel B: Earnings Announcement Abnormal Volume

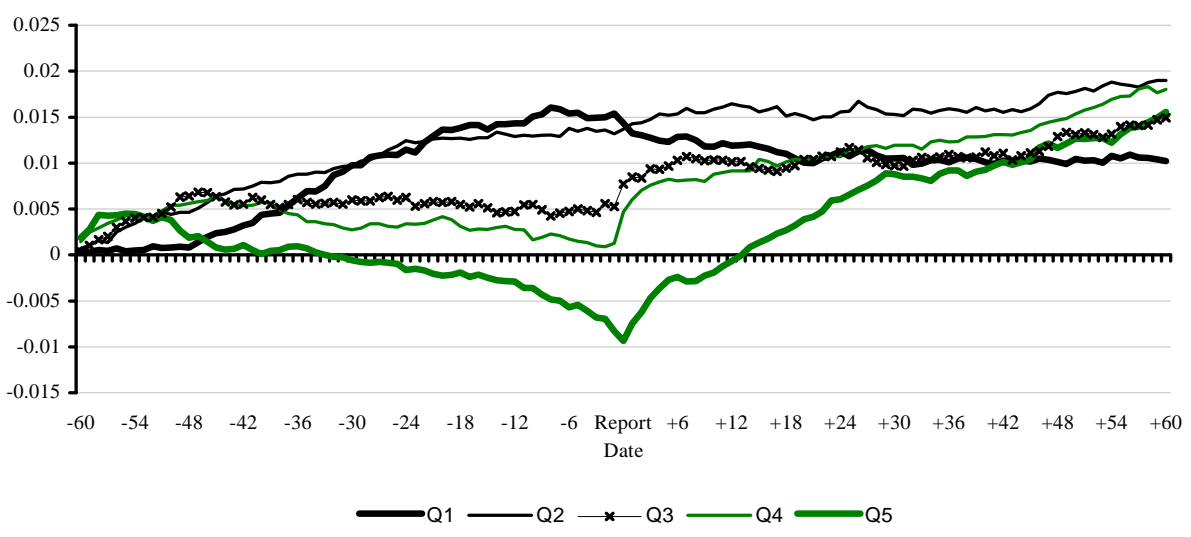


Figure 5: Long-Term Quintile Spread Performance

Figure 5 tracks, over a 300-day period, the cumulative difference in the long-term performance of stocks that fall in quintile 5 and quintile 1 of earnings announcement abnormal returns (Panel A) and abnormal volume (Panel B). The long-term performance of each stock is market-adjusted (Ex-Mkt) and characteristics-adjusted (Ex-Char). To compute the characteristics benchmark, we match each event firm to a portfolio of securities that fall in the same Size (market capitalization), Book-to-Market and Momentum terciles prior to the announcement.

\section{Panel A: Earnings Announcement Abnormal Return}

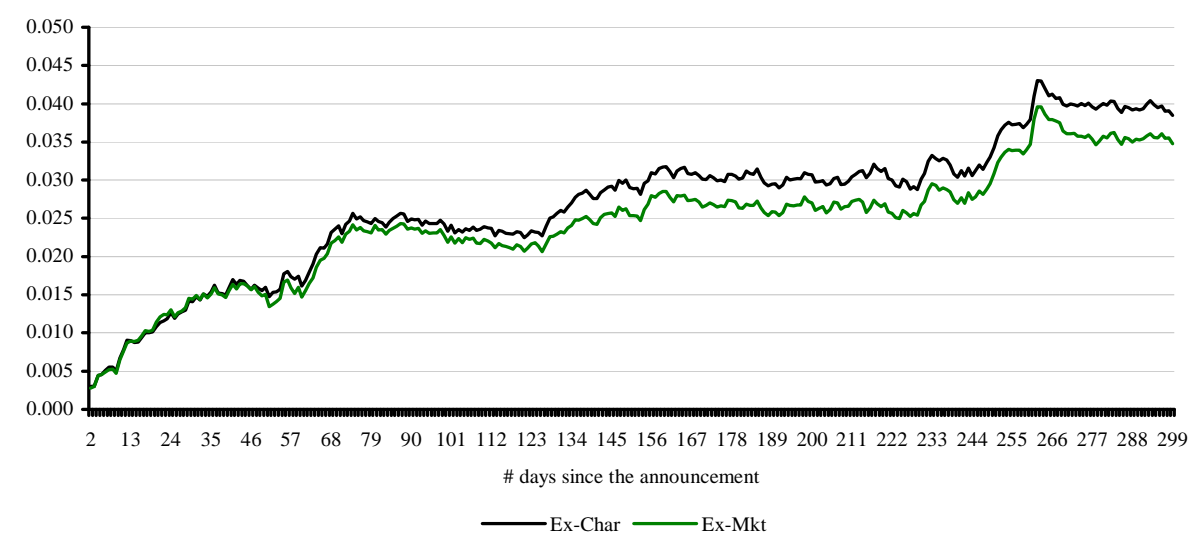

Panel B: Earnings Announcement Abnormal Volume

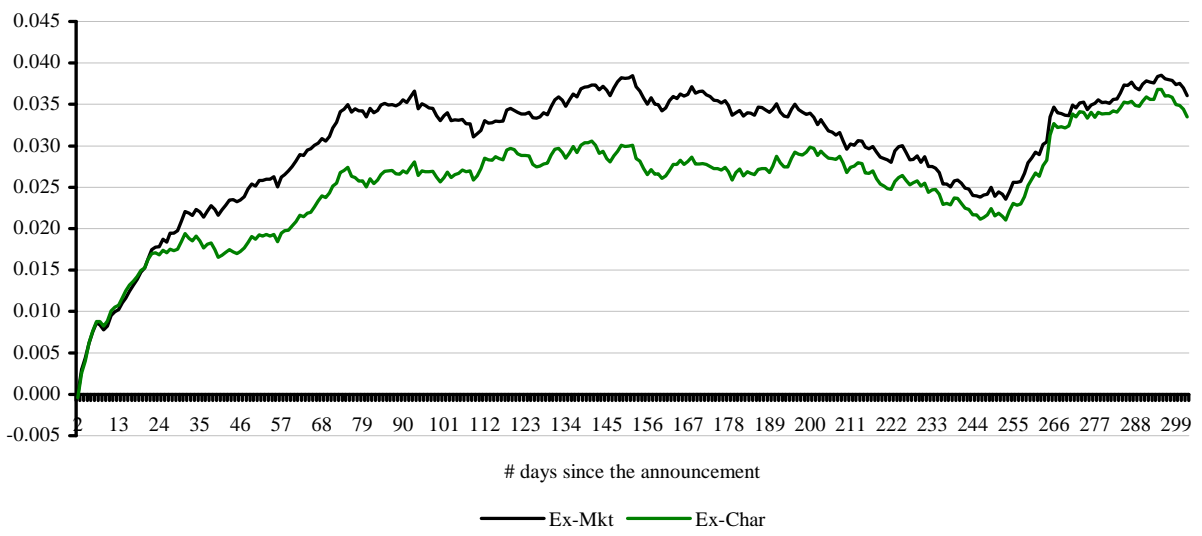


Figure 6: Long-Term Patterns in Abnormal Volume

Figure 6 shows the median abnormal volume of each quintile of earnings announcement abnormal volume, from 60 days to 300 days after the announcement. In Panel A, we keep the normal trading volume constant throughout the period. It is equal to the normal trading volume on the event date. In Panel B, we use a moving average over the post-event days.

\section{Panel A: Constant Normal Volume}

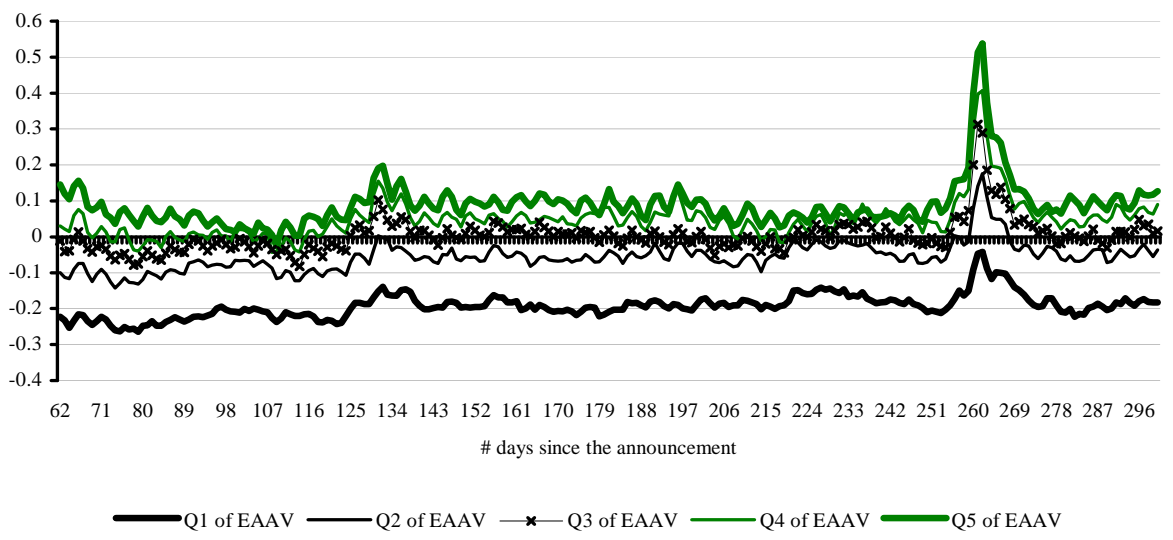

Panel B: Moving Normal Volume

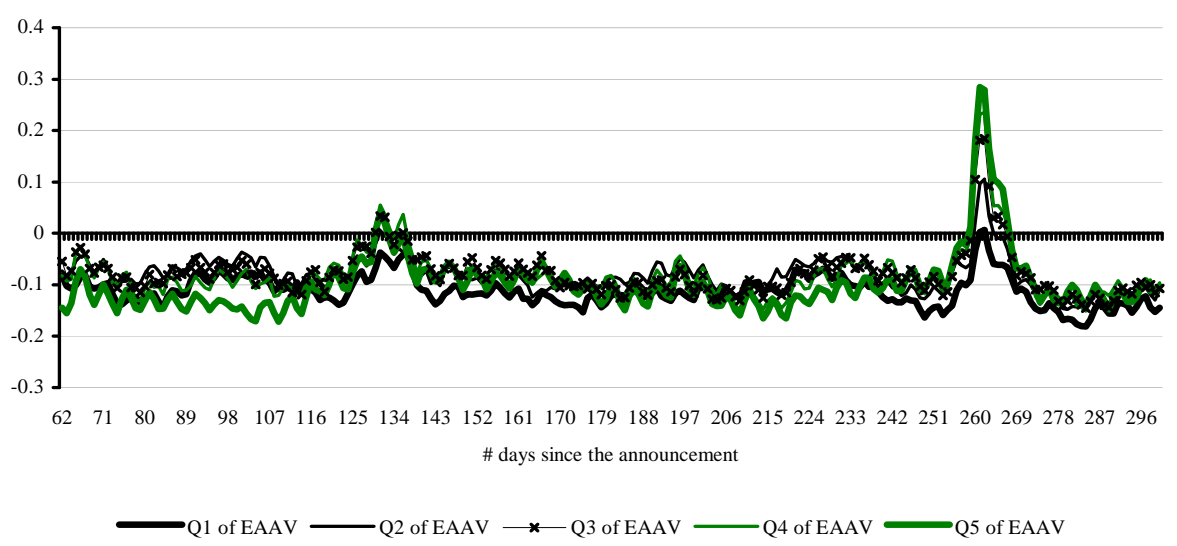


Figure 7: Dynamics of Aggregate Idiosyncratic Volatility

In Figure 7 we track the level of aggregate idiosyncratic volatility at the end of each month in our sample, as well as the dynamics of three idiosyncratic volatility benchmarks. The aggregate idiosyncratic volatility at the end of each month is equal to the square root of the equally weighted average of the idiosyncratic variance of stock returns for each index constituent, estimated using 52 weeks of data and the Carhart (1997) four-factor model of equation (3). The three benchmarks are computed, respectively, as the average weekly idiosyncratic risk from one year ago to four years ago ([-1Y, -4Y]), five years ago $([-1 \mathrm{Y},-5 \mathrm{Y}])$, or six years ago $([-1 \mathrm{Y},-6 \mathrm{Y}])$. In turn, a period of high specific risk is one where the previous one-year average idiosyncratic risk is larger than the benchmark level. Finally, the values in Figure 7 have been annualised.

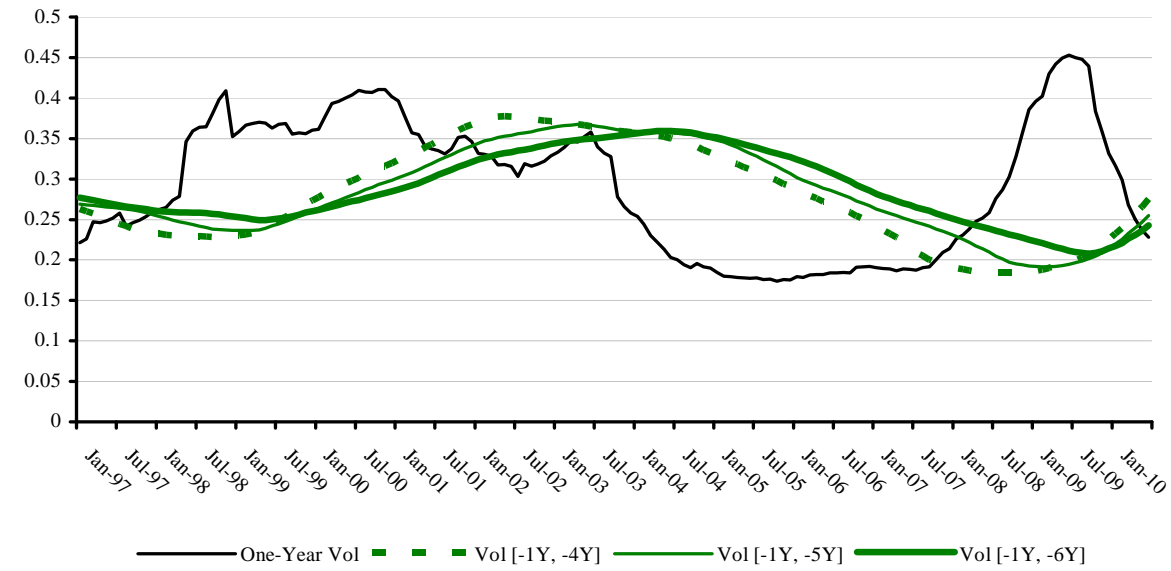

Figure 8: Trading Strategy With Monthly Rebalancing

Figure 8 describes the time sequence of ranking and trading periods for a trading strategy with monthly rebalancing. At the end of each month, we rank stocks on the basis of their latest earnings surprises, provided that the last announcement was made no later than four months ago. We then use those rankings to create a portfolio that we hold until the end of the following month, when the ranking process is repeated.

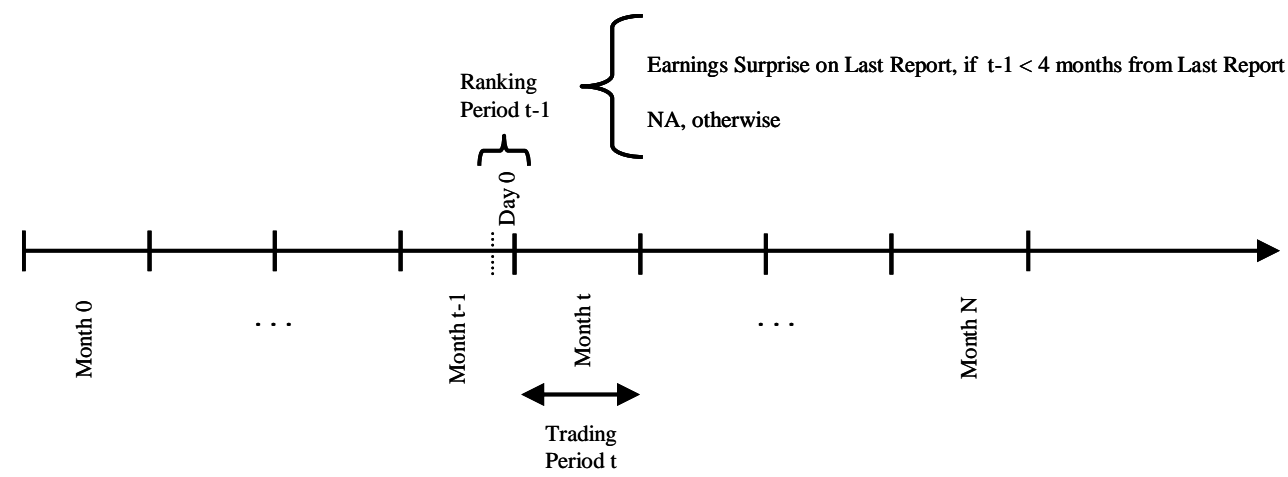


Table 1: Post-Earnings Announcement Drift

Table 1 shows the adjusted post-announcement returns of each quintile of firms ranked on their earnings announcement abnormal return (Panel A) and abnormal volume (Panel B). To avoid a lookahead bias, quintiles are formed on the basis of the past three months' values. Returns are marketadjusted (Ex-Mkt), and characteristics-adjusted (Ex-Char). To compute the characteristics benchmark, we match each event firm to a portfolio of securities that fall in the same Size (market capitalization), Book-to-Market and Momentum terciles prior to the announcement. Finally, to avoid biasing our statistical tests, we consider the earnings surprise of a firm only if its post-event returns do not overlap with those of its previous surprise.

Panel A: Earnings Announcement Abnormal Return

\begin{tabular}{lccccccc}
\hline \hline & Q1 & Q2 & Q3 & Q4 & Q5 & Q5-Q1 & t-stat \\
\hline Holding period: [+2,+6] & & & & & & & \\
Ex-Mkt & $-0.02 \%$ & $0.09 \%$ & $0.14 \%$ & $0.20 \%$ & $0.56 \%$ & $0.57 \%$ & $4.22 * * *$ \\
Ex-Char & $-0.04 \%$ & $0.05 \%$ & $0.17 \%$ & $0.19 \%$ & $0.51 \%$ & $0.55 \%$ & $4.10^{* * *}$ \\
Holding period: [+2,+21] & & & & & & & \\
Ex-Mkt & $-0.36 \%$ & $0.09 \%$ & $0.48 \%$ & $0.25 \%$ & $0.97 \%$ & $1.33 \%$ & $5.57 * * *$ \\
Ex-Char & $-0.40 \%$ & $-0.12 \%$ & $0.34 \%$ & $0.18 \%$ & $0.80 \%$ & $1.20 \%$ & $5.15^{* * *}$ \\
Holding period: [+2,+61] & & & & & & & \\
Ex-Mkt & $0.12 \%$ & $1.20 \%$ & $0.69 \%$ & $0.73 \%$ & $1.78 \%$ & $1.66 \%$ & $3.99 * * *$ \\
Ex-Char & $-0.61 \%$ & $0.17 \%$ & $-0.22 \%$ & $-0.12 \%$ & $0.99 \%$ & $1.60 \%$ & $4.11^{* * *}$ \\
\hline
\end{tabular}

Panel B: Earnings Announcement Abnormal Volume

\begin{tabular}{lccccccc}
\hline \hline & Q1 & Q2 & Q3 & Q4 & Q5 & Q5-Q1 & t-stat \\
\hline Holding period: [+2,+6] & & & & & & & \\
Ex-Mkt & $-0.01 \%$ & $0.12 \%$ & $0.23 \%$ & $0.12 \%$ & $0.53 \%$ & $0.54 \%$ & $4.39 * * *$ \\
Ex-Char & $0.03 \%$ & $0.13 \%$ & $0.18 \%$ & $0.10 \%$ & $0.51 \%$ & $0.49 \%$ & $4.04^{* * *}$ \\
Holding period: [+2,+21] & & & & & & & \\
Ex-Mkt & $-0.25 \%$ & $0.12 \%$ & $0.11 \%$ & $0.35 \%$ & $1.14 \%$ & $1.39 \%$ & $6.32^{* * *}$ \\
Ex-Char & $-0.16 \%$ & $-0.01 \%$ & $-0.12 \%$ & $0.23 \%$ & $0.90 \%$ & $1.06 \%$ & $4.96 * * *$ \\
Holding period: [+2,+61] & & & & & & & \\
Ex-Mkt & $-0.15 \%$ & $0.38 \%$ & $0.53 \%$ & $1.23 \%$ & $2.67 \%$ & $2.82 \%$ & $7.07 * * *$ \\
Ex-Char & $-0.61 \%$ & $-0.46 \%$ & $-0.41 \%$ & $0.57 \%$ & $1.16 \%$ & $1.77 \%$ & $4.79 * * *$ \\
\hline
\end{tabular}

*Significantly different from zero at the $10 \%$ level using a two-tailed test **Significantly different from zero at the $5 \%$ level using a two-tailed test ***Significantly different from zero at the $1 \%$ level using a two-tailed test 


\section{Table 2: Annual Post-Earnings Announcement Drift}

Table 2 reports market-adjusted post-announcement quintile spread returns (QS) based on earnings announcement abnormal return (Panel A) and abnormal volume (Panel B) rankings for each year in our sample. To avoid a look-ahead bias, quintiles are formed based on the past three months' values. Finally, to avoid biasing our statistical tests, we consider the earnings surprise of a firm only if its postevent returns do not overlap with those of its previous surprise.

Panel A: Earnings Announcement Abnormal Return

\begin{tabular}{ccccccc}
\hline \hline & \multicolumn{2}{c}{ Holding period: [+2,+6] } & \multicolumn{2}{c}{ Holding period: [+2,+21] } & \multicolumn{2}{c}{ Holding period: [+2,+61] } \\
& QS & t-stat & QS & t-stat & QS & t-stat \\
\hline 1997 & $0.44 \%$ & 0.93 & $-1.15 \%$ & -1.42 & $-2.26 \%$ & -1.38 \\
1998 & $0.85 \%$ & 1.62 & $1.04 \%$ & 1.21 & $4.92 \%$ & $3.79 * * *$ \\
1999 & $0.55 \%$ & 1.21 & $2.35 \%$ & $2.24 * * *$ & $1.63 \%$ & 0.83 \\
2000 & $0.54 \%$ & 0.76 & $2.00 \%$ & $1.81 *$ & $2.85 \%$ & 1.63 \\
2001 & $0.69 \%$ & 1.23 & $2.52 \%$ & $2.39 * * *$ & $1.12 \%$ & 0.68 \\
2002 & $-0.34 \%$ & -0.53 & $-0.05 \%$ & -0.05 & $2.59 \%$ & 1.69 \\
2003 & $0.72 \%$ & 1.24 & $2.34 \%$ & $2.87 * * *$ & $0.96 \%$ & 0.51 \\
2004 & $1.04 \%$ & $3.69 * * *$ & $1.95 \%$ & $4.18^{* * *}$ & $0.88 \%$ & 1.09 \\
2005 & $0.25 \%$ & 1.09 & $1.25 \%$ & $2.54 * * *$ & $1.99 \%$ & $2.29 * * *$ \\
2006 & $0.80 \%$ & $3.38 * * *$ & $1.19 \%$ & $2.30 * * *$ & $1.70 \%$ & $1.95 *$ \\
2007 & $0.79 \%$ & $2.53 * * *$ & $0.73 \%$ & 1.24 & $1.90 \%$ & $1.80 *$ \\
2008 & $0.76 \%$ & 1.33 & $1.67 \%$ & 1.7 & $2.94 \%$ & $1.75^{*}$ \\
2009 & $0.34 \%$ & 0.57 & $0.23 \%$ & 0.21 & $-1.90 \%$ & -0.9 \\
2010 & $0.33 \%$ & 0.69 & $1.06 \%$ & 1.21 & $0.10 \%$ & 0.06 \\
\hline Total & $0.57 \%$ & $4.22 * * *$ & $1.33 \%$ & $5.57 * * *$ & $1.66 \%$ & $3.99 * * *$ \\
\hline
\end{tabular}

Panel B: Earnings Announcement Abnormal Volume

\begin{tabular}{ccccccc}
\hline \hline & \multicolumn{2}{c}{ Holding period: [+2,+6] } & \multicolumn{2}{c}{ Holding period: [+2,+21] } & \multicolumn{2}{c}{ Holding period: [+2,+61] } \\
QS & t-stat & QS & t-stat & QS & t-stat \\
\hline 1997 & $-0.14 \%$ & -0.27 & $-1.48 \%$ & -1.26 & $-3.67 \%$ & $-1.96^{*}$ \\
1998 & $0.63 \%$ & 1.24 & $2.55 \%$ & $2.92^{* * *}$ & $1.89 \%$ & 1.26 \\
1999 & $1.11 \%$ & $2.60^{* * *}$ & $0.71 \%$ & 0.63 & $1.35 \%$ & 0.68 \\
2000 & $0.64 \%$ & 1.09 & $1.79 \%$ & $1.69 *$ & $2.90 \%$ & $1.84^{*}$ \\
2001 & $0.66 \%$ & 1.23 & $0.57 \%$ & 0.61 & $3.94 \%$ & $2.79^{* * *}$ \\
2002 & $1.97 \%$ & $3.36^{* * *}$ & $3.97 \%$ & $4.36^{* * *}$ & $5.50 \%$ & $4.22^{* * *}$ \\
2003 & $1.06 \%$ & $1.88^{*}$ & $2.50 \%$ & $2.99^{* * *}$ & $3.21 \%$ & $1.71^{*}$ \\
2004 & $0.15 \%$ & 0.6 & $-0.54 \%$ & -1.33 & $-1.69 \%$ & $-2.17^{* *}$ \\
2005 & $-0.10 \%$ & -0.45 & $-0.43 \%$ & -0.98 & $-0.39 \%$ & -0.45 \\
2006 & $0.18 \%$ & 0.75 & $0.31 \%$ & 0.62 & $1.90 \%$ & $2.33^{* *}$ \\
2007 & $0.55 \%$ & $1.75^{*}$ & $0.64 \%$ & 1.08 & $0.55 \%$ & 0.48 \\
2008 & $0.79 \%$ & 1.33 & $2.77 \%$ & $2.85^{* * *}$ & $3.71 \%$ & $2.14^{* *}$ \\
2009 & $0.83 \%$ & $1.70^{*}$ & $3.68 \%$ & $3.78^{* * *}$ & $9.40 \%$ & $4.92^{* * *}$ \\
2010 & $-0.43 \%$ & -0.88 & $1.36 \%$ & 1.58 & $9.00 \%$ & $5.04^{* * *}$ \\
\hline Total & $0.54 \%$ & $4.39 * * *$ & $1.39 \%$ & $6.32^{* * *}$ & $2.82 \%$ & $7.07^{* * *}$ \\
\hline
\end{tabular}

*Significantly different from zero at the $10 \%$ level using a two-tailed test

**Significantly different from zero at the 5\% level using a two-tailed test

$* * *$ Significantly different from zero at the $1 \%$ level using a two-tailed test 
Table 3:Long-Term Quintile Spread Performance

Table 3 tracks, over a 300-day period, the cumulative difference in the long-term performance of stocks that fall in quintile 5 and quintile 1 of earnings announcement abnormal returns (Panel A) and abnormal volume (Panel B). The long-term performance of each stock is market-adjusted, and characteristics-adjusted. To compute the characteristics benchmark, we match each event firm to a portfolio of securities that fall in the same Size (market capitalization), Book-to-Market and Momentum terciles prior to the announcement. To avoid biasing our statistical tests, we consider the earnings surprise of a firm only if its post-event returns do not overlap with those of its previous surprise. Finally, the 300-day post-announcement period is divided into 5 quarters of equal length, where the first quarter (quarter 0) corresponds to the 60-day period following the earnings announcement.

Panel A: Earnings Announcement Abnormal Return

\begin{tabular}{lllll}
\hline \hline & \multicolumn{2}{c}{ Market-Adjusted } & \multicolumn{2}{c}{ Characteristics-Adjusted } \\
\hline & QS & t-stat & QS & t-stat \\
Quarter 0 (Announcement) & $1.60 \%$ & $3.91^{* * *}$ & $1.73 \%$ & $4.35^{* * *}$ \\
Quarter 1 & $0.81 \%$ & $1.93^{*}$ & $0.86 \%$ & $2.06^{* *}$ \\
Quarter 2 & $0.26 \%$ & 0.60 & $0.55 \%$ & 1.29 \\
Quarter 3 & $0.02 \%$ & 0.04 & $-0.05 \%$ & -0.12 \\
Quarter 4 & $0.64 \%$ & $1.65^{*}$ & $0.77 \%$ & $1.93^{*}$ \\
\hline
\end{tabular}

Panel B: Earnings Announcement Abnormal Volume

\begin{tabular}{lcccc}
\hline \hline & \multicolumn{2}{c}{ Market-Adjusted } & \multicolumn{2}{c}{ Characteristics-Adjusted } \\
\hline & QS & t-stat & QS & t-stat \\
Quarter 0 (Announcement) & $2.77 \%$ & $6.97 * * *$ & $2.14 \%$ & $5.64 * * *$ \\
Quarter 1 & $0.41 \%$ & 1.05 & $0.81 \%$ & $2.07 * *$ \\
Quarter 2 & $0.09 \%$ & 0.23 & $-0.04 \%$ & -0.10 \\
Quarter 3 & $-0.62 \%$ & -1.52 & $-0.39 \%$ & -0.96 \\
Quarter 4 & $1.10 \%$ & $2.48 * * *$ & $1.18 \%$ & $2.70^{* * *}$ \\
\hline
\end{tabular}

*Significantly different from zero at the $10 \%$ level using a two-tailed test $* *$ Significantly different from zero at the $5 \%$ level using a two-tailed test ***Significantly different from zero at the $1 \%$ level using a two-tailed test 
Table 4: Information Uncertainty and the Premiums to Earnings Surprises

In Table 4 we explore the predictive power of earnings announcement abnormal returns (Panel A) and abnormal volume (Panel B) in each quintile of stock specific risk recorded at the time of the announcement. The predictive power of each measure of market surprise is assessed in terms of their market-adjusted and characteristics-adjusted quintile spread returns (QS). Finally, to avoid biasing our statistical tests, we consider the earnings surprise of a firm only if its post-event returns do not overlap with those of its previous surprise.

Panel A: Earnings Announcement Abnormal Return

\begin{tabular}{|c|c|c|c|c|c|c|c|}
\hline & \multicolumn{5}{|c|}{ Q Quintiles of Idiosyncratic Risk } & \multirow[b]{2}{*}{ Q5-Q1 } & \multirow[b]{2}{*}{ t-stat } \\
\hline & Q1 & Q2 & Q3 & Q4 & Q5 & & \\
\hline \multicolumn{8}{|c|}{ Holding Period $[+2,+6]$} \\
\hline QS (Ex-Mkt) & $0.51 \%$ & $-0.12 \%$ & $0.48 \%$ & $0.97 \%$ & $0.76 \%$ & $0.26 \%$ & 0.58 \\
\hline t-stat & 1.99 & -0.52 & 2.01 & 3.70 & 2.11 & & \\
\hline QS (Ex-Char) & $0.55 \%$ & $-0.03 \%$ & $0.43 \%$ & $0.84 \%$ & $0.74 \%$ & $0.18 \%$ & 0.42 \\
\hline t-stat & 2.15 & -0.12 & 1.77 & 3.20 & 2.10 & & \\
\hline \multicolumn{8}{|c|}{ Holding Period [+2, +21] } \\
\hline QS (Ex-Mkt) & $0.67 \%$ & $0.02 \%$ & $0.77 \%$ & $1.89 \%$ & $2.35 \%$ & $1.68 \%$ & $2.2^{* *}$ \\
\hline t-stat & 1.57 & 0.05 & 1.75 & 4.24 & 3.71 & & \\
\hline QS (Ex-Char) & $0.84 \%$ & $0.31 \%$ & $0.34 \%$ & $1.52 \%$ & $2.25 \%$ & $1.41 \%$ & $1.89 *$ \\
\hline t-stat & 1.93 & 0.73 & 0.78 & 3.48 & 3.69 & & \\
\hline \multicolumn{8}{|c|}{ Holding Period $[+2,+61]$} \\
\hline QS (Ex-Mkt) & $0.73 \%$ & $1.22 \%$ & $-0.32 \%$ & $1.95 \%$ & $4.04 \%$ & $3.31 \%$ & $2.55^{* *}$ \\
\hline t-stat & 1.00 & 1.76 & -0.43 & 2.42 & 3.77 & & \\
\hline QS (Ex-Char) & $1.20 \%$ & $1.33 \%$ & $-0.89 \%$ & $2.00 \%$ & $3.71 \%$ & $2.51 \%$ & $2.04 * *$ \\
\hline t-stat & 1.63 & 1.98 & -1.23 & 2.66 & 3.77 & & \\
\hline
\end{tabular}

Panel B: Earnings Announcement Abnormal Volume

\begin{tabular}{|c|c|c|c|c|c|c|c|}
\hline & \multicolumn{5}{|c|}{ "Quintiles of Idiosyncratic Risk } & \multirow[b]{2}{*}{ Q5-Q1 } & \multirow[b]{2}{*}{ t-stat } \\
\hline & Q1 & Q2 & Q3 & Q4 & Q5 & & \\
\hline \multicolumn{8}{|c|}{ Holding Period $[+2,+6]$} \\
\hline QS (Ex-Mkt) & $0.23 \%$ & $0.13 \%$ & $0.42 \%$ & $0.72 \%$ & $1.52 \%$ & $1.29 \%$ & $3.02 * * *$ \\
\hline t-stat & 1.08 & 0.59 & 1.60 & 2.60 & 4.08 & & \\
\hline QS (Ex-Char) & $0.16 \%$ & $0.13 \%$ & $0.50 \%$ & $0.77 \%$ & $1.32 \%$ & $1.16 \%$ & $2.78 * * *$ \\
\hline t-stat & 0.77 & 0.63 & 1.92 & 2.84 & 3.68 & & \\
\hline \multicolumn{8}{|c|}{ Holding Period $[+2,+21]$} \\
\hline QS (Ex-Mkt) & $1.27 \%$ & $1.41 \%$ & $1.47 \%$ & $1.08 \%$ & $2.43 \%$ & $1.16 \%$ & 1.50 \\
\hline t-stat & 3.33 & 3.68 & 2.99 & 2.14 & 3.62 & & \\
\hline QS (Ex-Char) & $1.20 \%$ & $0.98 \%$ & $1.38 \%$ & $1.10 \%$ & $1.87 \%$ & $0.67 \%$ & 0.90 \\
\hline t-stat & 3.12 & 2.57 & 2.83 & 2.20 & 2.94 & & \\
\hline \multicolumn{8}{|c|}{ Holding Period $[+2,+61]$} \\
\hline QS (Ex-Mkt) & $1.66 \%$ & $1.92 \%$ & $3.21 \%$ & $2.74 \%$ & $3.83 \%$ & $2.17 \%$ & $1.65 *$ \\
\hline t-stat & 2.69 & 2.74 & 3.85 & 3.05 & 3.30 & & \\
\hline QS (Ex-Char) & $1.78 \%$ & $1.19 \%$ & $2.83 \%$ & $1.83 \%$ & $2.14 \%$ & $0.36 \%$ & 0.30 \\
\hline t-stat & 2.87 & 1.74 & 3.49 & 2.13 & 2.11 & & \\
\hline
\end{tabular}

*Significantly different from zero at the $10 \%$ level using a two-tailed test $* *$ Significantly different from zero at the $5 \%$ level using a two-tailed test $* * *$ Significantly different from zero at the $1 \%$ level using a two-tailed test 
Table 5: Idiosyncratic Volatility Regimes and the Premiums to Earnings Surprises

In Table 5 we look at the performance of the earnings announcement abnormal return (Panel A) and abnormal volume (Panel B) strategies following periods of high and low aggregate specific risk. A period of high specific risk is one where the previous one-year average weekly idiosyncratic risk is larger than the average weekly idiosyncratic risk from one year ago to four years ago ([-1Y, $-4 \mathrm{Y}])$, five years ago ([-1Y, $-5 \mathrm{Y}])$, or six years ago ([-1Y, $-6 \mathrm{Y}])$. To avoid a look ahead bias, a surprise is classified into a high or low state of aggregate idiosyncratic risk based on the market state prevailing at the end of the month preceding the earnings announcement. The predictive power of both measures of market surprise is assessed, over each regime, in terms of their market-adjusted (Ex-Mkt) and characteristics-adjusted (Ex-Char) quintile spread returns (QS).

Finally, to avoid biasing our statistical tests, we consider the earnings surprise of a firm only if its post-event returns do not overlap with those of its previous surprise.

\section{Panel A: Earnings Announcement Abnormal Return}

\begin{tabular}{|c|c|c|c|c|c|c|c|}
\hline & & \multicolumn{2}{|c|}{ Holding Period $[+2,+6]$} & \multicolumn{2}{|c|}{ Holding Period $[+2,+21]$} & \multicolumn{2}{|c|}{ Holding Period $[+2,+61]$} \\
\hline & & Ex-Mkt & Ex-Char & Ex-Mkt & Ex-Char & Ex-Mkt & Ex-Char \\
\hline \multicolumn{8}{|c|}{$\begin{array}{l}\text { Normal Idiosyncratic Volatility [-1Y, }-4 \mathrm{Y}] \\
\end{array}$} \\
\hline \multirow{2}{*}{ High Regime } & QS & $0.62 \%$ & $0.60 \%$ & $1.32 \%$ & $1.13 \%$ & $1.82 \%$ & $1.68 \%$ \\
\hline & t-stat & $2.90^{* * *}$ & $2.85^{* * *}$ & $3.46 * * *$ & $3.05^{* * *}$ & $2.74^{* * *}$ & $2.72^{* * *}$ \\
\hline \multirow[t]{2}{*}{ Low Regime } & QS & $0.52 \%$ & $0.49 \%$ & $1.33 \%$ & $1.25 \%$ & $1.51 \%$ & $1.52 \%$ \\
\hline & t-stat & $3.10^{* * *}$ & $2.96 * * *$ & $4.69 * * *$ & $4.478^{* * * *}$ & $3.00^{* * * *}$ & $3.19 * * *$ \\
\hline \multirow{2}{*}{ Difference } & QS & $0.09 \%$ & $0.11 \%$ & $0.00 \%$ & $-0.12 \%$ & $0.30 \%$ & $0.15 \%$ \\
\hline & t-stat & 0.34 & 0.43 & -0.01 & -0.25 & 0.36 & 0.20 \\
\hline \multicolumn{8}{|c|}{ Normal Idiosyncratic Volatility [-1Y, -5Y] } \\
\hline \multirow[t]{2}{*}{ High Regime } & QS & $0.60 \%$ & $0.54 \%$ & $1.57 \%$ & $1.28 \%$ & $1.91 \%$ & $1.74 \%$ \\
\hline & t-stat & $2.68^{* * *}$ & $2.44 * *$ & $3.92 * * *$ & $3.30^{* * *}$ & $2.79 * * *$ & $2.73^{* * *}$ \\
\hline \multirow[t]{2}{*}{ Low Regime } & QS & $0.56 \%$ & $0.56 \%$ & $1.10 \%$ & $1.12 \%$ & $1.44 \%$ & $1.47 \%$ \\
\hline & t-stat & $3.52^{* * *}$ & $3.66 * * *$ & $4.21 * * *$ & $4.31^{* * *}$ & $3.00^{* * *}$ & $3.24 * * *$ \\
\hline \multirow[t]{2}{*}{ Difference } & QS & $0.04 \%$ & $-0.03 \%$ & $0.47 \%$ & $0.16 \%$ & $0.48 \%$ & $0.27 \%$ \\
\hline & t-stat & 0.14 & -0.10 & 0.98 & 0.33 & 0.57 & 0.34 \\
\hline \multicolumn{8}{|c|}{ Normal Idiosyncratic Volatility [-1Y, -6Y] } \\
\hline \multirow[t]{2}{*}{ High Regime } & QS & $0.55 \%$ & $0.48 \%$ & $1.36 \%$ & $1.07 \%$ & $1.71 \%$ & $1.53 \%$ \\
\hline & t-stat & $2.44^{* *}$ & $2.14^{* *}$ & $3.41^{* * *}$ & $2.78^{* * *}$ & $2.43^{* *}$ & $2.38^{* *}$ \\
\hline \multirow[t]{2}{*}{ Low Regime } & QS & $0.60 \%$ & $0.62 \%$ & $1.29 \%$ & $1.32 \%$ & $1.63 \%$ & $1.68 \%$ \\
\hline & t-stat & $3.97 * * *$ & $4.21^{* * *}$ & $5.04 * * *$ & $5.15^{* * *}$ & $3.631^{* * *}$ & $3.82^{* * *}$ \\
\hline \multirow[t]{2}{*}{ Difference } & QS & $-0.05 \%$ & $-0.15 \%$ & $0.06 \%$ & $-0.25 \%$ & $0.08 \%$ & $-0.14 \%$ \\
\hline & t-stat & -0.19 & -0.55 & 0.14 & -0.54 & 0.09 & -0.18 \\
\hline
\end{tabular}

\section{Panel B: Earnings Announcement Abnormal Volume}

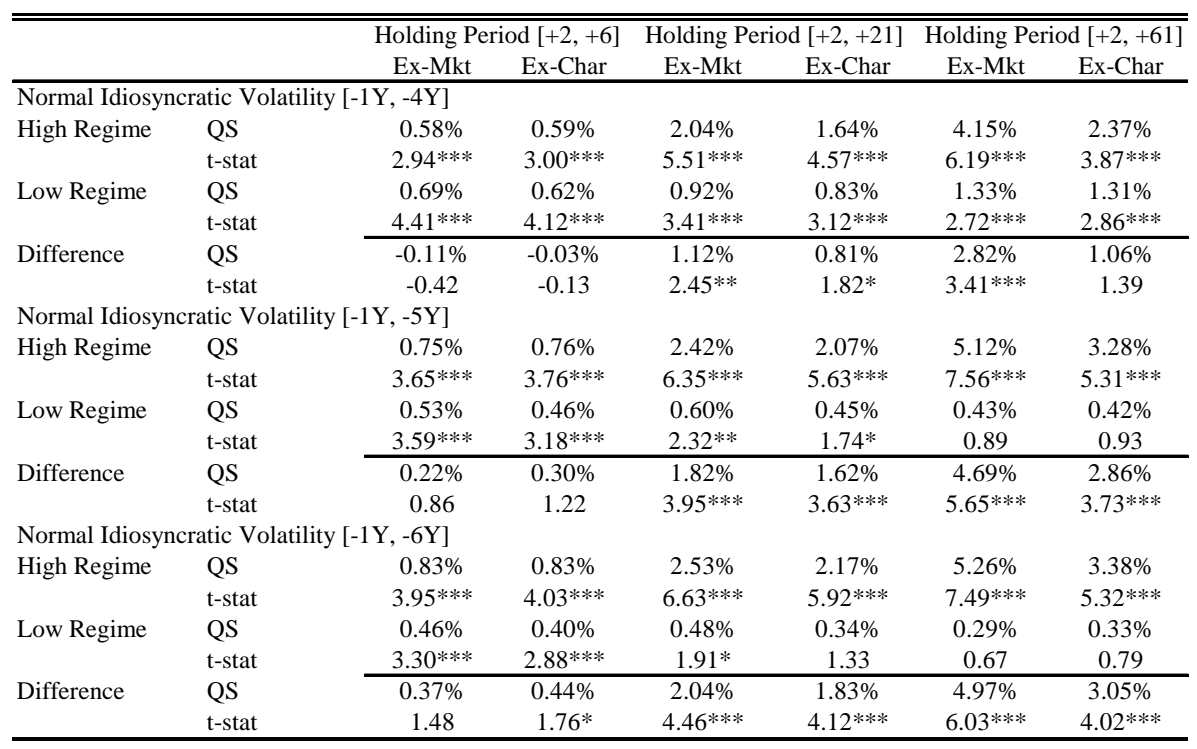

*Significantly different from zero at the $10 \%$ level using a two-tailed test **Significantly different from zero at the $5 \%$ level using a two-tailed test

$* * *$ Significantly different from zero at the $1 \%$ level using a two-tailed test 
Table 6: Intersecting Earnings Announcement Abnormal Return and Abnormal Volume Rankings

In Table 6 we intersect independent rankings based on earnings announcement abnormal return and abnormal volume, and measure over different holding periods the marketadjusted (Panel A) and characteristics-adjusted (Panel B) performance of each intersection. To avoid a look-ahead bias, quintiles are formed on the basis of the past three months' values. Finally, to avoid biasing our statistical tests, we consider the earnings surprise of a firm only if its post-event returns do not overlap with those of its previous surprise.

\section{Panel A: Market-Adjusted Returns}

Holding Period $[+2,+6]$

\begin{tabular}{|c|c|c|c|c|c|c|c|c|}
\hline \multicolumn{9}{|c|}{ A Abnormal Volume } \\
\hline \multirow{8}{*}{ 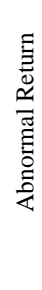 } & & $\overline{\mathrm{Q} 1}$ & $\overline{\mathrm{Q} 2}$ & Q3 & Q4 & Q5 & $\overline{Q S}$ & t-stat \\
\hline & Q1 & $0.03 \%$ & $-0.06 \%$ & $0.12 \%$ & $-0.36 \%$ & $0.12 \%$ & $0.09 \%$ & 0.22 \\
\hline & Q2 & $-0.03 \%$ & $0.02 \%$ & $0.03 \%$ & $0.09 \%$ & $0.15 \%$ & $0.18 \%$ & 0.69 \\
\hline & Q3 & $-0.13 \%$ & $0.12 \%$ & $0.31 \%$ & $0.17 \%$ & $0.52 \%$ & $0.65 \%$ & $2.21 * *$ \\
\hline & Q4 & $-0.20 \%$ & $0.10 \%$ & $0.42 \%$ & $0.10 \%$ & $0.74 \%$ & $0.94 \%$ & $3.57 * * *$ \\
\hline & Q5 & $-0.38 \%$ & $0.49 \%$ & $0.19 \%$ & $0.58 \%$ & $0.96 \%$ & $1.34 \%$ & $3.36 * * *$ \\
\hline & QS & $-0.41 \%$ & $0.55 \%$ & $0.07 \%$ & $0.94 \%$ & $0.84 \%$ & & \\
\hline & t-stat & -0.81 & 1.54 & 0.22 & $3.49 * * *$ & $3.43 * * *$ & & \\
\hline
\end{tabular}

Holding Period [+2,+21]

\begin{tabular}{|c|c|c|c|c|c|c|c|c|}
\hline \multicolumn{9}{|c|}{ Abnormal Volume } \\
\hline & & Q1 & Q2 & $\mathrm{Q}^{3}$ & Q4 & Q5 & QS & t-stat \\
\hline & Q1 & $-1.00 \%$ & $-0.77 \%$ & $-0.62 \%$ & $-0.45 \%$ & $0.09 \%$ & $1.09 \%$ & $1.66 *$ \\
\hline & Q2 & $-0.44 \%$ & $-0.19 \%$ & $0.15 \%$ & $0.33 \%$ & $1.02 \%$ & $1.46 \%$ & $2.76^{* * *}$ \\
\hline & Q3 & $0.04 \%$ & $0.34 \%$ & $0.18 \%$ & $0.98 \%$ & $1.42 \%$ & $1.38 \%$ & $2.57 * *$ \\
\hline & Q4 & $-0.59 \%$ & $0.27 \%$ & $0.35 \%$ & $0.52 \%$ & $1.37 \%$ & $1.96 \%$ & $4.13^{* * *}$ \\
\hline & Q5 & $-0.50 \%$ & $0.98 \%$ & $0.28 \%$ & $0.58 \%$ & $1.97 \%$ & $2.47 \%$ & $2.62 * * *$ \\
\hline & Q & $0.50 \%$ & 1.7 & $0.90 \%$ & $1.03 \%$ & $1.88 \%$ & & \\
\hline & & 0.47 & ** & 4* & $24 *$ & & & \\
\hline
\end{tabular}

\section{Panel B: Characteristics-Adjusted Returns}

Holding Period $[+2,+6]$

\begin{tabular}{|c|c|c|c|c|c|c|c|c|}
\hline & & & & ormal V & lume & & & \\
\hline & & $\mathrm{Q} 1$ & $\overline{\mathrm{Q} 2}$ & $\overline{\mathrm{Q} 3}$ & $\mathrm{Q} 4$ & Q5 & $\overline{\mathrm{QS}}$ & t-stat \\
\hline & Q1 & $0.03 \%$ & $-0.19 \%$ & $0.17 \%$ & $-0.41 \%$ & $0.07 \%$ & $0.04 \%$ & 0.11 \\
\hline & Q2 & $-0.07 \%$ & $0.00 \%$ & $-0.01 \%$ & $0.10 \%$ & $0.11 \%$ & $0.18 \%$ & 0.70 \\
\hline & Q3 & $-0.10 \%$ & $0.27 \%$ & $0.27 \%$ & $0.17 \%$ & $0.69 \%$ & $0.79 \%$ & $2.80^{* * *}$ \\
\hline & Q4 & $-0.12 \%$ & $0.09 \%$ & $0.31 \%$ & $0.15 \%$ & $0.73 \%$ & $0.85 \%$ & $3.27^{* * *}$ \\
\hline & Q5 & $-0.34 \%$ & $0.47 \%$ & $0.11 \%$ & $0.50 \%$ & $0.91 \%$ & $1.25 \%$ & $3.19^{* * *}$ \\
\hline & QS & $-0.37 \%$ & $0.66 \%$ & $-0.06 \%$ & $0.91 \%$ & $0.84 \%$ & & \\
\hline & t-stat & -0.74 & $1.84 *$ & 0.20 & $10 * * *$ & $49^{* * *}$ & & \\
\hline
\end{tabular}

\begin{tabular}{|c|c|c|c|c|c|c|c|c|}
\hline \multicolumn{9}{|c|}{$x_{1}$} \\
\hline \multirow{8}{*}{ 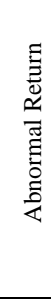 } & & Q1 & Q2 & $\mathrm{Q} 3$ & $\mathrm{Q} 4$ & $\mathrm{Q} 5$ & $\mathrm{QS}$ & t-stat \\
\hline & Q1 & $-0.72 \%$ & $-1.25 \%$ & $-0.71 \%$ & $-0.42 \%$ & $-0.04 \%$ & $0.68 \%$ & 1.08 \\
\hline & Q2 & $-0.50 \%$ & $-0.29 \%$ & $0.04 \%$ & $0.04 \%$ & $0.25 \%$ & $0.75 \%$ & 1.48 \\
\hline & Q3 & $-0.07 \%$ & $0.41 \%$ & $-0.19 \%$ & $0.87 \%$ & $1.17 \%$ & $1.25 \%$ & $2.33 * * *$ \\
\hline & Q4 & $-0.40 \%$ & $0.04 \%$ & $0.07 \%$ & $0.41 \%$ & $1.20 \%$ & $1.60 \%$ & $3.55 * * *$ \\
\hline & $\underline{Q 5}$ & $-0.62 \%$ & $0.96 \%$ & $-0.01 \%$ & $0.43 \%$ & $1.79 \%$ & $2.41 \%$ & $2.65^{* * *}$ \\
\hline & QS & $0.10 \%$ & $2.20 \%$ & $0.69 \%$ & $0.85 \%$ & $1.83 \%$ & & \\
\hline & t-stat & 0.10 & $3.32 * * *$ & 1.42 & $1.84 *$ & $4.55^{* * * *}$ & & \\
\hline
\end{tabular}

Holding Period [+2,+61]

\begin{tabular}{|c|c|c|c|c|c|c|c|c|}
\hline \multicolumn{9}{|c|}{ 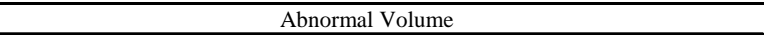 } \\
\hline \multirow{8}{*}{ 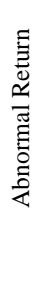 } & & $\mathrm{Q} 1$ & $\mathrm{Q} 2$ & $\mathrm{Q} 3$ & $\mathrm{Q} 4$ & Q5 & $\mathrm{QS}$ & t-stat \\
\hline & Q1 & $-1.10 \%$ & $-0.60 \%$ & $0.18 \%$ & $0.71 \%$ & $0.93 \%$ & $2.03 \%$ & $2.07 * *$ \\
\hline & Q2 & $-0.04 \%$ & $0.72 \%$ & $1.08 \%$ & $1.37 \%$ & $4.98 \%$ & $5.01 \%$ & $4.32^{* * * *}$ \\
\hline & Q3 & $-0.43 \%$ & $0.36 \%$ & $0.68 \%$ & $1.77 \%$ & $3.20 \%$ & $3.64 \%$ & $3.69 * * *$ \\
\hline & Q4 & $0.24 \%$ & $0.47 \%$ & $0.18 \%$ & $1.56 \%$ & $2.06 \%$ & $1.81 \%$ & $2.02 * *$ \\
\hline & Q5 & $0.67 \%$ & $0.79 \%$ & $0.55 \%$ & $1.06 \%$ & $3.68 \%$ & $3.01 \%$ & $2.19^{* *}$ \\
\hline & Q & $\%$ & $1.39 \%$ & $0.36 \%$ & $0.35 \%$ & $2.75 \%$ & & \\
\hline & & 18 & 24 & 41 & .40 & & & \\
\hline
\end{tabular}

Holding Period [+2,+61]

\begin{tabular}{|c|c|c|c|c|c|c|c|c|}
\hline \multicolumn{9}{|c|}{ Abnormal Volume } \\
\hline \multirow{7}{*}{ 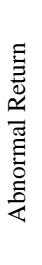 } & & Q1 & Q2 & Q3 & Q4 & $\mathrm{Q5}$ & $\mathrm{QS}$ & t-stat \\
\hline & Q1 & $-1.16 \%$ & $-1.83 \%$ & $-0.89 \%$ & $0.42 \%$ & $-0.19 \%$ & $0.98 \%$ & 1.08 \\
\hline & Q2 & $-0.49 \%$ & $-0.21 \%$ & $0.31 \%$ & $0.54 \%$ & $1.86 \%$ & $2.35 \%$ & $2.29 * *$ \\
\hline & Q3 & $-1.30 \%$ & $-0.09 \%$ & $-0.52 \%$ & $1.19 \%$ & $0.97 \%$ & $2.27 \%$ & $2.37 * *$ \\
\hline & Q4 & $-0.46 \%$ & $-0.67 \%$ & $-0.71 \%$ & $0.44 \%$ & $1.13 \%$ & $1.59 \%$ & $1.85 *$ \\
\hline & $\mathrm{Q} 5$ & $-0.04 \%$ & $0.28 \%$ & $-0.33 \%$ & $0.45 \%$ & $2.31 \%$ & $2.35 \%$ & $1.90 *$ \\
\hline & QS & $1.12 \%$ & $\%$ & $5 \%$ & $0.04 \%$ & $2.50 \%$ & & \\
\hline
\end{tabular}

*Significantly different from zero at the $10 \%$ level using a two-tailed test **Significantly different from zero at the $5 \%$ level using a two-tailed test

$* * *$ Significantly different from zero at the $1 \%$ level using a two-tailed test 
Table 7:Performance of Earnings Surprise Strategy

Table 7 shows the quintile spread performance of a strategy built around earnings announcement surprises. At the end of each month, we rank stocks on the basis of their latest earnings surprises, provided that the last announcement was made no later than four months ago. We then use those rankings to create a quintile spread portfolio that we hold until the end of the following month, when the ranking process is repeated. We assess the performance of this strategy within the whole sample of stocks as well as various subsets of our investable universe. We distinguish between large cap names (LC) and small cap names (SC), depending on whether the market capitalisation of a stock falls above or below the median value at the portfolio formation date. Within the large cap subset, we also investigate the performance of the earnings surprise strategy for those stocks with an illiquidity ratio that falls in the bottom $50 \%$ of values for that group (LC and High Liquidity, HL). Finally, the sample is divided, each month, into two groups of equal size, according to the idiosyncratic volatility of the stocks just prior to their earnings announcement date (LV: Low Volatility, and HV: High Volatility). We present the raw performance of the strategies, as well as their characteristics-adjusted average monthly returns (Ex-Char). To compute the characteristics benchmark, we match each firm to a portfolio of securities that fall in the same Size (market capitalization), Book-to-Market and Momentum terciles.

\begin{tabular}{|c|c|c|c|c|c|c|c|c|}
\hline & & "Q1 & 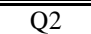 & "Q3 & QQ4 & QQ5 & "Q5-Q1 & t-stat \\
\hline \multirow[t]{2}{*}{ Earnings Surprise } & Raw Returns & $0.32 \%$ & $0.65 \%$ & $0.56 \%$ & $0.71 \%$ & $1.02 \%$ & $0.70 \%$ & $4.59^{* * *}$ \\
\hline & Ex-Char & $-0.36 \%$ & $-0.01 \%$ & $-0.06 \%$ & $-0.03 \%$ & $0.33 \%$ & $0.69 \%$ & $4.86 * * *$ \\
\hline \multirow[t]{2}{*}{ Earnings Surprise (SC) } & Raw Returns & $0.26 \%$ & $0.68 \%$ & $0.62 \%$ & $0.86 \%$ & $1.10 \%$ & $0.84 \%$ & $3.63^{* * *}$ \\
\hline & Ex-Char & $-0.50 \%$ & $-0.06 \%$ & $-0.03 \%$ & $0.05 \%$ & $0.31 \%$ & $0.81 \%$ & $3.46 * * *$ \\
\hline \multirow[t]{2}{*}{ Earnings Surprise (LC) } & Raw Returns & $0.36 \%$ & $0.64 \%$ & $0.50 \%$ & $0.64 \%$ & $0.95 \%$ & $0.58 \%$ & $3.21^{* * *}$ \\
\hline & Ex-Char & $-0.25 \%$ & $0.00 \%$ & $-0.09 \%$ & $-0.01 \%$ & $0.30 \%$ & $0.56 \%$ & $3.21 * * *$ \\
\hline \multirow[t]{2}{*}{ Earnings Surprise (LV) } & Raw Returns & $0.43 \%$ & $0.71 \%$ & $0.73 \%$ & $0.72 \%$ & $0.95 \%$ & $0.52 \%$ & $3.38 * * *$ \\
\hline & Ex-Char & $-0.17 \%$ & $0.07 \%$ & $0.08 \%$ & $0.05 \%$ & $0.24 \%$ & $0.41 \%$ & $2.82 * * *$ \\
\hline \multirow[t]{2}{*}{ Earnings Surprise (HV) } & Raw Returns & $0.23 \%$ & $0.45 \%$ & $0.50 \%$ & $0.73 \%$ & $1.10 \%$ & $0.87 \%$ & $3.83^{* * *}$ \\
\hline & Ex-Char & $-0.52 \%$ & $-0.23 \%$ & $-0.12 \%$ & $-0.05 \%$ & $0.39 \%$ & $0.91 \%$ & $4.27 * * *$ \\
\hline \multirow[t]{2}{*}{ Earnings Surprise (LC and HL) } & Raw Returns & $0.42 \%$ & $0.75 \%$ & $0.37 \%$ & $0.44 \%$ & $0.98 \%$ & $0.56 \%$ & $2.56^{* *}$ \\
\hline & Ex-Char & $-0.15 \%$ & $0.13 \%$ & $-0.11 \%$ & $-0.11 \%$ & $0.38 \%$ & $0.54 \%$ & $2.48^{* *}$ \\
\hline
\end{tabular}

*Significantly different from zero at the $10 \%$ level using a two-tailed test **Significantly different from zero at the $5 \%$ level using a two-tailed test ***Significantly different from zero at the $1 \%$ level using a two-tailed test 
Table 8: The Earnings Surprise Strategy and the Fama-French / Carhart Factors

In Table 8 we present the results of regression analyses of portfolio returns on the Fama-French / Carhart risk factors for the European market. The dependent variable in these regressions is the monthly return of a quintile spread strategy built around earnings announcement surprises. At the end of each month, we rank stocks on the basis of their latest earnings surprises, provided that the last announcement was made no later than four months ago. We then use those rankings to create a quintile spread portfolio that we hold until the end of the following month, when the ranking process is repeated. Various specifications of the strategy are being considered. We assess its performance within the whole sample of stocks as well as different subsets of our investable universe. We distinguish between large cap names (LC) and small cap names (SC), depending on whether the market capitalisation of a stock falls above or below the median value at the portfolio formation date. Finally, the sample is divided, each month, into two groups of equal size, according to the idiosyncratic volatility of the stocks just prior to their earnings announcement date (LV: Low Volatility, and HV: High Volatility).

\begin{tabular}{llccccc}
\hline \hline & & Alpha (\%) & Market & SMB & HML & UMD \\
\hline Earnings Surprise & Coeff & $0.42 \%$ & 0.034 & 0.143 & -0.103 & 0.070 \\
& t-stat & $2.72 * * *$ & 0.97 & $1.74^{*}$ & $-2.00^{* *}$ & $2.16^{* *}$ \\
Earnings Surprise (SC) & Coeff & $0.47 \%$ & -0.027 & 0.097 & 0.059 & 0.099 \\
& t-stat & $1.97^{* *}$ & -0.50 & 0.77 & 0.75 & $1.99^{* *}$ \\
Earnings Surprise (LC) & Coeff & $0.35 \%$ & 0.045 & 0.170 & -0.164 & 0.032 \\
& t-stat & $1.91 *$ & 1.09 & $1.76^{*}$ & $-2.71^{* * *}$ & 0.83 \\
Earnings Surprise (LV) & Coeff & $0.18 \%$ & 0.016 & -0.040 & 0.019 & 0.072 \\
& t-stat & 1.17 & 0.46 & -0.49 & 0.37 & $2.19^{* *}$ \\
Earnings Surprise (HV) & Coeff & $0.58 \%$ & 0.088 & 0.291 & -0.133 & 0.067 \\
& t-stat & $2.52^{* *}$ & $1.70^{*}$ & $2.39^{* *}$ & $-1.74^{*}$ & 1.39 \\
\hline
\end{tabular}

*Significantly different from zero at the $10 \%$ level using a two-tailed test **Significantly different from zero at the $5 \%$ level using a two-tailed test ***Significantly different from zero at the $1 \%$ level using a two-tailed test 
Table 9: Idiosyncratic Volatility Regimes and the Earnings Surprise Strategy

In Table 9 we look at the performance of a quintile spread strategy based on earnings surprises following periods of high and low aggregate specific risk. A period of high aggregate specific risk is one where the previous one-year average weekly idiosyncratic risk is larger than the average weekly idiosyncratic risk from one year ago to four years ago ([-1Y, $-4 \mathrm{Y}])$, five years ago $([-1 \mathrm{Y},-5 \mathrm{Y}])$, or six years ago ([-1Y, -6Y]). We present the raw performance of the strategy, as well as its characteristicsadjusted average monthly return (Ex-Char). To compute the characteristics benchmark, we match each firm to a portfolio of securities that fall in the same Size (market capitalization), Book-to-Market and Momentum terciles.

\begin{tabular}{lcccccc}
\hline \hline & \multicolumn{2}{c}{ Normal Volatility [-1Y, -4Y] } & \multicolumn{2}{c}{ Normal Volatility [-1Y, -5Y] } & \multicolumn{2}{c}{ Normal Volatility [-1Y, -6Y] } \\
& Raw Returns & Ex-Char & Raw Returns & Ex-Char & Raw Returns & Ex-Char \\
\hline High Regime & $0.97 \%$ & $0.88 \%$ & $1.16 \%$ & $1.11 \%$ & $1.26 \%$ & $1.19 \%$ \\
Low Regime & $0.44 \%$ & $0.50 \%$ & $0.27 \%$ & $0.29 \%$ & $0.14 \%$ & $0.18 \%$ \\
\cline { 2 - 7 } Difference & $0.53 \%$ & $0.39 \%$ & $0.89 \%$ & $0.82 \%$ & $1.12 \%$ & $1.01 \%$ \\
t-stat & $1.73^{*}$ & 1.36 & $2.94 * * *$ & $2.94 * * *$ & $3.82 * * *$ & $3.73^{* * *}$ \\
\hline
\end{tabular}

*Significantly different from zero at the $10 \%$ level using a two-tailed test **Significantly different from zero at the $5 \%$ level using a two-tailed test ***Significantly different from zero at the $1 \%$ level using a two-tailed test

Table 10: Earnings Announcement Abnormal Volume and Absolute Returns

Table 10 shows the quintile spread performance of strategies based on earnings announcement abnormal volume and absolute return (AAR). In addition to considering the raw abnormal volume at the time of the announcement, we also control for the level of absolute return via some monthly crosssectional regressions. Two types of regressions are run, the first one treats all returns equally (1), and the second one distinguishes between positive and negative returns (2). At the end of each month, we rank stocks on the basis of each measure, provided that the last announcement was made no later than four months ago. We then use those rankings to create quintile spread portfolios that we hold until the end of the following month, when the ranking process is repeated. We present the raw performance of the strategies, as well as their characteristics-adjusted average monthly returns (Ex-Char). To compute the characteristics benchmark, we match each firm to a portfolio of securities that fall in the same Size (market capitalization), Book-to-Market and Momentum terciles.

\begin{tabular}{llccccccc}
\hline \hline & & Q1 & Q2 & Q3 & Q4 & Q5 & Q5-Q1 & t-stat \\
\hline Abnormal Volume & Raw Returns & $0.35 \%$ & $0.60 \%$ & $0.67 \%$ & $0.79 \%$ & $0.86 \%$ & $0.51 \%$ & $2.85 * * *$ \\
& Ex-Char & $-0.25 \%$ & $-0.10 \%$ & $-0.06 \%$ & $0.15 \%$ & $0.13 \%$ & $0.38 \%$ & $2.53 * *$ \\
Abnormal Volume ex AAR (1) & Raw Returns & $0.39 \%$ & $0.42 \%$ & $0.71 \%$ & $0.87 \%$ & $0.88 \%$ & $0.49 \%$ & $2.92 * * *$ \\
& Ex-Char & $-0.23 \%$ & $-0.23 \%$ & $0.01 \%$ & $0.16 \%$ & $0.16 \%$ & $0.39 \%$ & $2.69 * * *$ \\
Abnormal Volume ex AAR (2) & Raw Returns & $0.39 \%$ & $0.47 \%$ & $0.67 \%$ & $0.87 \%$ & $0.88 \%$ & $0.48 \%$ & $2.93 * * *$ \\
& Ex-Char & $-0.23 \%$ & $-0.18 \%$ & $-0.05 \%$ & $0.18 \%$ & $0.15 \%$ & $0.38 \%$ & $2.67 * * *$ \\
AAR & Raw Returns & $0.52 \%$ & $0.70 \%$ & $0.61 \%$ & $0.62 \%$ & $0.70 \%$ & $0.18 \%$ & 0.71 \\
& Ex-Char & $-0.14 \%$ & $-0.03 \%$ & $-0.03 \%$ & $-0.09 \%$ & $0.04 \%$ & $0.18 \%$ & 0.99 \\
\hline
\end{tabular}

* Significantly different from zero at the $10 \%$ level using a two-tailed test **Significantly different from zero at the $5 \%$ level using a two-tailed test $* * *$ Significantly different from zero at the $1 \%$ level using a two-tailed test 